\title{
Inflammatory diseases in dairy cows: Risk factors and associations with pregnancy after embryo transfer
}

\author{
I. N. F. Edelhoff, ${ }^{1,2} \oplus$ M. H. C. Pereira, ${ }^{2}$ J. J. Bromfield, ${ }^{1,3} \oplus$ J. L. M. Vasconcelos, ${ }^{2} \oplus$ and J. E. P. Santos ${ }^{1,3 *}$ (1) \\ ${ }^{1}$ Department of Animal Sciences, University of Florida, Gainesville 32611 \\ 2Department of Animal Production, São Paulo State University, Botucatu, Brazil 18168 \\ ${ }^{3} \mathrm{DH}$ Barron Reproductive and Perinatal Biology Research Program, University of Florida, Gainesville 32611
}

\begin{abstract}
The objectives of the present prospective cohort study were to identify risk factors for inflammatory diseases in Holstein-Gyr crossbred dairy cows and characterize the associations of those diseases with pregnancy per embryo transfer (ET). Diseases were diagnosed in the first $60 \mathrm{~d}$ postpartum in 252 primiparous and 481 multiparous cows. Uterine diseases (UTD) included retained placenta, metritis, clinical endometritis, and subclinical endometritis. Nonuterine diseases (NUTD) included mastitis, lameness, pneumonia, and displaced abomasum. Blood was sampled on d 0,1 , and 2 postpartum and analyzed for concentrations of haptoglobin, fatty acids, total $\mathrm{Ca}$ (tCa), $\mathrm{P}$, and $\mathrm{Mg}$, and again on $\mathrm{d} 8$ postpartum and analyzed for concentration of $\beta$-hydroxybutyrate. The association between concentrations of metabolites in serum and inflammatory diseases was determined. Cows received a timed ET program starting $28 \pm 3 \mathrm{~d}$ postpartum with first ET at $46 \pm 3 \mathrm{~d}$ postpartum using fresh in vitro-produced embryos. Pregnancy was diagnosed on $\mathrm{d} 31$ and 59 of presumptive gestation. Overall, $63.3 \%$ of the cows were diagnosed with UTD and $20.6 \%$ with NUTD. The risk factors for UTD included season of calving, parity group, calving problems, days with subclinical hypocalcemia, and serum concentrations of haptoglobin and $\mathrm{Mg}$, whereas the risk factors for NUTD were parity group and serum $\mathrm{Mg}$ concentration. Cows that developed UTD had increased concentrations of haptoglobin on d 2 and fatty acids on d 1 and 2, and reduced concentrations of tCa on $\mathrm{d} 1$ and 2 and of $\mathrm{P}$ and $\mathrm{Mg}$ on $\mathrm{d}$ 2 postpartum compared with cows without UTD. Cows that developed NUTD had increased concentrations of fatty acids on d 0 to 2 postpartum, and decreased concentrations of tCa and $\mathrm{P}$ on $\mathrm{d} 0$ and 1 , and of $\mathrm{Mg}$
\end{abstract}

Received June 10, 2020.

Accepted July 14, 2020.

*Corresponding author: jepsantos@ufl.edu on $\mathrm{d} 1$ and 2 postpartum compared with cows without NUTD. Cows that developed NUTD had a $340-\mathrm{kg}$ reduction in milk yield in the first $60 \mathrm{~d}$ postpartum. Inflammatory diseases were associated with lesser body condition score and increased loss of body condition in the first $70 \mathrm{~d}$ postpartum. Maintenance of pregnancy after ET was reduced in UTD cows following the first (41.7 vs. $25.4 \%$ ) or all ET (46.4 vs. $36.2 \%$ ), whereas maintenance of pregnancy was reduced in NUTD cows only at the second ET (39.0 vs $25.9 \%)$. The reduced pregnancy maintenance in UTD cows combined with a reduced 21 -d service rate (61.9 vs. $54.8 \%$ ) decreased the 21-d cycle pregnancy rate (28.6 vs. $19.9 \%$ ) and the hazard of pregnancy to $300 \mathrm{~d}$ postpartum by $35 \%$, resulting in an extra $32 \mathrm{~d}$ open. In conclusion, inflammatory diseases depressed fertility in dairy cows receiving ET, with the greatest impact observed in UTD cows. This suggests that local inflammation of the uterus impairs maintenance of pregnancy in dairy cows following ET. Key words: dairy cow, embryo transfer, inflammation, reproduction

\section{INTRODUCTION}

Calving and the onset of lactation are events that often result in inflammation in dairy cows (Bradford et al., 2015). Calving causes trauma, which increases the risk of uterine diseases (Vieira-Neto et al., 2016). Approximately 30 to $45 \%$ of postpartum cows develop some type of clinical disease in the first 30 to $60 \mathrm{~d}$ in lactation (Santos et al., 2010; Ribeiro et al., 2016; Carvalho et al., 2019), and most postpartum diseases are associated with reduced fertility (Santos et al., 2010; Ribeiro et al., 2016; Carvalho et al., 2019). Uterine diseases (UTD) are accompanied by signs of local or systemic illness (Sheldon et al., 2009). Similarly, mastitis, a nonuterine disease (NUTD) often diagnosed in early lactation, can lead to systemic signs of illness (Wenz et al., 2001). These early lactation diseases are associated with events that take place before or immediately after calving, and to some extent, they have common 
links such as negative nutrient balance and alterations in measures of immune function (Banos et al., 2013).

A common aspect of UTD and NUTD is sickness behavior with reduced DMI and the concurrent inflammatory response (Sheldon et al., 2009; Pérez-Báez et al., 2019). Pathogens and the resulting inflammatory response cause release of molecular patterns that stimulate residing immune cells to release cytokines (Sheldon et al., 2009; Bromfield et al., 2015), which, in turn, upregulate hepatic secretion of positive acute phase proteins (Cray et al., 2009). Furthermore, reduced DMI increases lipomobilization and reduces nutrient balance. Thus, it is not surprising that altered concentrations of biomarkers in blood have been associated with the risk of postpartum diseases in dairy cows (Huzzey et al., 2009; Chapinal et al., 2012; Martinez et al., 2012).

Diseases and concurrent inflammation affect reproduction in part because of disrupted endocrine signaling and perturbations in follicle or oocyte development (Sheldon et al., 2009; Bromfield et al., 2015). Cows that develop diseases in early lactation are more likely to have an extended anovulatory period (Santos et al., 2010). Uterine inflammation transiently reduces oocyte competence to develop to the morula stage embryo (Dickson et al., 2020). Also, inflammation creates a hostile uterine environment that prevents proper conceptus development (Ribeiro et al., 2016), thereby resulting in increased pregnancy loss (Santos et al., 2010). It is interesting that conceptuses from cows that had inflammatory diseases express molecular signatures compatible with inflammation (Ribeiro et al., 2016), suggesting shifts in the transcriptome that might compromise conceptus survival. These molecular changes in reproductive tissues are observed even months after induced uterine inflammation (Horlock et al., 2020).

One method to circumvent the impacts of disease on fertility is the use of embryo transfer (ET). Also, synchronizing ovulation should minimize the impact of diseases mediated by anovulation. Therefore, timed ET allows for the evaluation of the association between diseases and maintenance of pregnancy, independent of early events needed to establish pregnancy in dairy cows. Inflammatory diseases affect pregnancy in dairy cattle receiving AI, although the underlying mechanisms are complex and multifaceted. Less is known about the impact of inflammatory diseases on maintenance of pregnancy following ET (Ribeiro et al., 2016; Barbosa et al., 2018; Estrada-Cortés et al., 2019). Segregating diseases into those that affect the uterus or other tissues may provide insight on potential underlying mechanisms of inflammation-associated subfertility that are directly linked to the reproductive tract or with systemic effects of inflammation.
It was hypothesized that periparturient events and plasma metabolites are risk factors for inflammatory diseases and that UTD and NUTD affect maintenance of pregnancy in an additive manner in crossbred dairy cows. Therefore, the objectives of the present study were to identify risk factors for inflammatory diseases in Holstein-Gyr crossbred dairy cows and characterize the association of those diseases with pregnancy per ET $(\mathbf{P} / \mathbf{E T})$ in the first $300 \mathrm{~d}$ postpartum.

\section{MATERIALS AND METHODS}

All procedures involving cows in this experiment were approved by the São Paulo State University regulatory animal research system committee (protocol number: CEUA-0060/2019) and followed the recommendations of the Guide for the Care and Use of Agricultural Animals in Agricultural Research and Teaching (accessed at https://www.adsa.org/Portals/_default/SiteContent/ docs/AgGuide3rd/Chapter07.pdf).

\section{Cows, Housing, and Management}

The study was conducted on a commercial dairy farm milking approximately 1,600 cows in the state of Minas Gerais, Brazil, at a latitude of $20.72^{\circ}$ South and longitude of $46.61^{\circ}$ West. The farm was visited daily and weekly cohorts of cows were enrolled from August 2018 to January 2019. A total of 733 crossbred Holstein-Gyr dairy cows, 252 primiparous and 481 multiparous, were enrolled in the study on the day of calving. Cows calving in the months of August and September were considered to have calved in the cool season (daily mean temperature $<23^{\circ} \mathrm{C}$ ), whereas those calving between October and January were considered to have calved in the hot season (daily mean temperature $>25^{\circ} \mathrm{C}$ ).

All cows were either 50\% Holstein and 50\% Gyr (76 primiparous and 163 multiparous) or $75 \%$ Holstein and $25 \%$ Gyr (176 primiparous and 318 multiparous) derived from in vitro-produced embryos using in vivocollected oocytes from purebred Gyr or $50 \%$ Holstein and 50\% Gyr donors and fertilized with Holstein Xsorted semen from North American genetics.

Cows were housed in a compost barn during the last 3 wk of gestation and in another compost barn during the first $74.8 \pm 13.1 \mathrm{~d}$ postpartum (ranged from 48 to $171 \mathrm{~d}$, median $72 \mathrm{~d}$ ). For the remainder of lactation, cows were on irrigated pastures of perennial Bermudagrass 'Tifton 85' (Cynodon spp.). Prepartum and early postpartum cows housed indoors received diets as TMR (Table 1), whereas once on pasture, cows received the same grain mix used in the TMR that was fed at a rate 
Table 1. Diets fed to cows prepartum and early postpartum ${ }^{1}$

\begin{tabular}{|c|c|c|}
\hline Item & Prepartum $^{2}$ & $\begin{array}{c}\text { Early } \\
\text { postpartum }^{3}\end{array}$ \\
\hline \multicolumn{3}{|l|}{ Ingredient } \\
\hline Corn silage & 74.9 & 37.9 \\
\hline Elephant grass silage & 4.9 & 2.5 \\
\hline Whole cottonseed & 3.7 & 7.4 \\
\hline Cracked corn & 1.5 & 0.6 \\
\hline Soybean meal & 13.2 & 10.0 \\
\hline Citrus pulp & - & 4.0 \\
\hline Grain mix & - & 34.9 \\
\hline \multicolumn{3}{|l|}{ Mineral and vitamin } \\
\hline Prepartum ${ }^{5}$ & 2.0 & - \\
\hline Postpartum $^{6}$ & - & 2.7 \\
\hline \multicolumn{3}{|c|}{ Nutrient content, ${ }^{7} \mathrm{DM}$ basis } \\
\hline $\mathrm{OM}, \%$ & $92.8 \pm 1.5$ & $93.4 \pm 1.0$ \\
\hline $\mathrm{CP}, \%$ & $15.6 \pm 1.2$ & $17.6 \pm 1.1$ \\
\hline $\mathrm{NDF}, \%$ of $\mathrm{OM}$ & $34.9 \pm 3.2$ & $26.0 \pm 1.0$ \\
\hline Ether extract, \% & $3.2 \pm 0.2$ & $3.3 \pm 0.6$ \\
\hline NFC, $\%$ & $39.1 \pm 2.2$ & $46.5 \pm 2.4$ \\
\hline $\mathrm{Ca}, \%$ & $0.72 \pm 0.11$ & $0.86 \pm 0.13$ \\
\hline $\mathrm{P}, \%$ & $0.34 \pm 0.05$ & $0.37 \pm 0.03$ \\
\hline $\mathrm{K}, \%$ & $1.43 \pm 0.14$ & $1.14 \pm 0.18$ \\
\hline $\mathrm{Mg}, \%$ & $0.27 \pm 0.01$ & $0.23 \pm 0.02$ \\
\hline $\mathrm{Na}, \%$ & $0.10 \pm 0.01$ & $0.22 \pm 0.04$ \\
\hline $\mathrm{Cl}, \%$ & $0.40 \pm 0.05$ & $0.50 \pm 0.08$ \\
\hline S, $\%$ & $0.22 \pm 0.03$ & $0.17 \pm 0.02$ \\
\hline $\mathrm{DCAD}, \mathrm{mEq} / \mathrm{kg}$ & $161 \pm 25$ & $136 \pm 42$ \\
\hline
\end{tabular}

${ }^{1}$ Samples collected weekly and composited for chemical analyses. Means and SD from chemical analysis of 4 composite samples per diet. ${ }^{2}$ Diet fed in the last 3 wk of gestation.

${ }^{3}$ Diet fed in the first 74 DIM.

${ }^{4}$ Each kilogram contained (DM basis) $63.0 \%$ ground corn, $20.3 \%$ soybean hulls, $9.9 \%$ soybean meal, $4.6 \%$ dried citrus pulp, $0.9 \%$ urea, $0.6 \%$ sodium chloride, and $0.7 \%$ sodium bentonite. The nutrient content (DM basis) was $16.4 \% \mathrm{CP}, 21.2 \% \mathrm{NDF}, 47.6 \%$ starch, $57.7 \%$ NFC, $3.6 \%$ fat, and $2.7 \%$ ash.

${ }^{5}$ Each kilogram contained (DM basis) $190 \mathrm{~g}$ of Ca, $17 \mathrm{~g}$ of P, $80 \mathrm{~g}$ of $\mathrm{Mg}, 30 \mathrm{~g}$ of Na, $40 \mathrm{~g}$ of S, 2,400 mg of Zn, 1,500 $\mathrm{mg}$ of Mn, 1,200 mg of $\mathrm{Cu}, 30 \mathrm{mg}$ of I, $16 \mathrm{mg}$ of $\mathrm{Co}, 12 \mathrm{mg}$ of Se, $36 \mathrm{mg}$ of $\mathrm{Cr}, 75 \mathrm{mg}$ of biotin, $750,000 \mathrm{IU}$ of vitamin $\mathrm{A}, 250,000 \mathrm{IU}$ of vitamin $\mathrm{D}_{3}, 7,500 \mathrm{IU}$ of vitamin $\mathrm{E}$, and $750 \mathrm{mg}$ of sodium monensin.

${ }^{6}$ Each kilogram contained (DM basis) $220 \mathrm{~g}$ of Ca, $40 \mathrm{~g}$ of P, $25 \mathrm{~g}$ of $\mathrm{Mg}, 65 \mathrm{~g}$ of Na, $10 \mathrm{~g}$ of S, 2,375 $\mathrm{mg}$ of $\mathrm{Zn}, 2,375 \mathrm{mg}$ of $\mathrm{Mn}, 562 \mathrm{mg}$ of $\mathrm{Cu}, 31 \mathrm{mg}$ of I, $13 \mathrm{mg}$ of Co, $15 \mathrm{mg}$ of Se, $57 \mathrm{mg}$ of biotin, 100,000 IU of vitamin $\mathrm{A}, 25,000 \mathrm{IU}$ of vitamin $\mathrm{D}_{3}, 625 \mathrm{IU}$ of vitamin $\mathrm{E}$, and 750 $\mathrm{mg}$ of sodium monensin.

${ }^{7}$ Values are means $\pm \mathrm{SD}$

of $1 \mathrm{~kg}$ per $2.7 \mathrm{~kg}$ of milk produced during each milking. The amount of grain mix fed to cows on pasture was adjusted twice monthly and pastures were managed in a rotational grazing system to have at least $15 \mathrm{~kg}$ of DM forage available per cow daily.

\section{Characterization and Diagnosis of Health Problems and Survival}

The hour of calving was recorded, and cows were observed for shedding of the placenta twice daily, at 12-h intervals. Cows that had not shed the placenta by $24 \mathrm{~h}$ after calving were considered to have retained fetal membranes. Cows that required assistance at calving were considered to have dystocia. The number of calves born and whether the calf was born alive or died immediately after birth was recorded. Cows with dystocia, stillbirth, or twins were considered to have calving problems. The hour of calving was categorized into 4 periods of $6 \mathrm{~h}$ each, from 0001 to $0600 \mathrm{~h}, 0601$ to 1200 h, 1201 to $1800 \mathrm{~h}$, and 1801 to $0000 \mathrm{~h}$ to characterize the distribution of calvings throughout the day.

Cows were evaluated for metritis on $\mathrm{d} 8 \pm 3$ postpartum by scoring the vaginal mucus using a vaginal mucus collection device (Metricheck, Simcro, New Zealand) concurrent with evaluation of rectal temperature and transrectal palpation. Metritis was characterized by fetid watery red-brown vaginal discharge (Sheldon et al., 2009), and cows with metritis and fever, based on rectal temperature $>39.5^{\circ} \mathrm{C}$, were considered to have puerperal metritis. Clinical endometritis was evaluated on d $21 \pm 3$ and $28 \pm 3$ postpartum by transrectal ultrasonography of the uterus to identify the presence of uterine content. Cows with visible uterine content had vaginal mucus scored using the Metricheck device. Cows with echogenic uterine content or those with vaginal discharge score $>2$, on a 0 to 5 scale, were considered to have clinical endometritis (McDougall et al., 2007). The cut-point of vaginal discharge score to classify cows as having clinical endometritis was based on the depression in pregnancy rate observed by McDougall et al. (2007). Subclinical endometritis was evaluated on $\mathrm{d} 28 \pm 3$ postpartum by endometrial cytology using the cytobrush technique (Lima et al., 2013). A total of 200 cells were counted on the cytological slide and the proportion of PMN was determined. Subclinical endometritis was characterized when PMN constituted $>9 \%$ of cells on the cytological slide (Galvão et al., 2009).

From parturition until 60 DIM, mastitis, lameness, digestive, and respiratory problems were evaluated for all cows. All cows were examined for signs of clinical mastitis by the herd personnel immediately before each milking by stripping each quarter. Clinical mastitis was characterized by the presence of abnormal milk or by signs of inflammation in one or more quarters. Upon diagnosis of mastitis, a milk sample was collected aseptically from the affected quarter into a vial, which was identified and stored under refrigeration. Once daily, milk samples were cultured using a combination of media (blood agar, Edwards medium, and MacConkey) followed by Gram staining and biochemical assays for identification of the bacterial agent. Digestive problems included diarrhea, bloat, or displacement of abomasum. Respiratory problems were characterized as increased respiratory frequency associated with fever 
and detection of lung sounds such as wheezing, rhonchi, or crackling sounds at auscultation. Cows were scored twice for lameness (Sprecher et al., 1997), once on the day of calving and again at $28 \pm 3$ DIM, and those that stood and walked with an arched back and had short strides in one or more legs (lameness score $>2$ ) were classified as clinically lame. Except for clinical mastitis and calving problems, all other diseases were diagnosed by veterinarians in the research team during daily visits to the farm for data collection.

Cows were considered to have had inflammatory diseases if they were diagnosed with those that affected the uterus (UTD), which included retained fetal membranes, metritis, clinical endometritis, or subclinical endometritis; or those that affected other tissues defined as nonuterine diseases (NUTD), which included mastitis, displaced abomasum, respiratory disease, and lameness. Because cows could develop multiple diseases, many of those that had UTD also developed NUTD and vice versa. The DIM when a cow had the diagnosis of the first and the last disease event in the first 60 postpartum were recorded. Cows that left the herd because they died or were culled were recorded for the first 300 DIM.

Blood Sampling and Analyses. Blood was sampled from all cows immediately after calving and again on $\mathrm{d} 1$ and 2 postpartum. A third sample was collected once weekly on $\mathrm{d} 8 \pm 3$ postpartum. On $\mathrm{d} 0,1$, and 2 , blood was collected by puncture of the coccygeal vessels into evacuated tubes with no additives (Vacutainer systems, Becton Dickinson, Franklin Lakes, NJ). Blood tubes were maintained at ambient temperature for 30 min for clotting and then placed in ice and transported to the laboratory within $3 \mathrm{~h}$ of collection. Tubes were centrifuged at 2,000 $\times g$ for 15 min for serum separation. Serum samples were frozen at $-20^{\circ} \mathrm{C}$ and later analyzed for concentrations of haptoglobin, fatty acids, total $\mathrm{Ca}$ (tCa), $\mathrm{Mg}$, and P. Blood collected on d $8 \pm 3$ was sampled from the coccygeal vessels and analyzed for concentrations of BHB in whole blood using a handheld meter for whole blood (KetoVet, ECO Diagnóstica, Nova Lima, MG, Brazil).

Concentrations of haptoglobin were assayed in serum by the colorimetric method based on peroxidase activity (Cooke and Arthington, 2013) and serum concentrations of fatty acids using a commercial kit (NEFA-C kit, Wako Diagnostics Inc., Richmond, VA) following the modifications by Johnson and Peters (1993). Concentrations of $\mathrm{tCa}$ and $\mathrm{Mg}$ were determined by atomic absorption spectrophotometer (AAnalyst 200, PerkinElmer Inc., Waltham, MA) according to Martinez et al. (2012). Concentrations of $\mathrm{P}$ were quantified using the molybdenum blue method (Quinlan and DeSesa,
1955). Control serum samples with predetermined large and small concentrations of the analytes were used to evaluate intra- and interassay coefficients of variation. The average intra- and interassay coefficients of variation were, respectively, 3.2 and $8.1 \%$ for haptoglobin, 5.5 and $4.0 \%$ for fatty acids, 1.2 and $1.4 \%$ for tCa, 1.0 and $2.3 \%$ for $\mathrm{Mg}$, and 3.7 and $4.3 \%$ for P. Cows were considered to have subclinical hypocalcemia when serum tCa $<2.00 \mathrm{~m} M$ (Reinhardt et al., 2011).

Body Condition Score and Milk Yield. Cows were scored for body condition using a 1 to 5 scale with increments of 0.25 units as depicted in the Elanco BCS chart (Elanco Animal Health, 2009) at calving, and at $28 \pm 3$ and $70 \pm 3 \mathrm{~d}$ postpartum by the same person. Cows were milked twice daily, at 12-h intervals, and daily milk yield for the first $60 \mathrm{~d}$ postpartum was recorded for individual cows using milk meters (Flow indicator FI7, DeLaval Ltda., São Paulo, Brazil).

\section{Reproductive Management}

All breedings in the first 300 DIM were performed using timed ET. Embryos were produced in a commercial laboratory (In Vitro Brazil, Uberaba, MG, Brazil) with oocytes from purebred Gyr or crossbred 50\% Gyr and $50 \%$ Holstein donor cows and X-sorted Holstein semen. Grade 1 morulae, early blastocysts, blastocysts, and expanded blastocysts were shipped fresh to the farm once a week and transferred on the same day.

The voluntary waiting period was $46 \pm 3$ DIM. Starting at $28 \pm 3$ DIM, cows had their estrous cycle and ovulation synchronized with a protocol as follows: d 0 , i.m. injection of $2.0 \mathrm{mg}$ of estradiol benzoate (Gonadiol; $1.0 \mathrm{mg} / \mathrm{mL}$ of estradiol benzoate; Zoetis, São Paulo, Brazil) and placement of an intravaginal progesterone insert (controlled internal drug release, CIDR-B, $1.9 \mathrm{~g}$ of progesterone, Zoetis); d 7, i.m. injections of $25 \mathrm{mg}$ of $\mathrm{PGF}_{2 \alpha}$ (Lutalyse; $5.0 \mathrm{mg} / \mathrm{mL}$ of dinoprost as tromethamine salt; Zoetis) and $300 \mathrm{IU}$ of equine chorionic gonadotropin (Novormon; $200 \mathrm{IU} / \mathrm{mL}$ of equine chorionic gonadotropin; Zoetis); d 9, removal of the progesterone insert and i.m. injections of $12.5 \mathrm{mg}$ of $\mathrm{PGF}_{2 \alpha}$ and 1.0 $\mathrm{mg}$ of estradiol cypionate $(2.0 \mathrm{mg} / \mathrm{mL}$ of estradiol cypionate; Zoetis). Two days later, on d 11 of the estrous synchronization protocol, it was anticipated to be d 0 of a new estrous cycle. All treatments were performed in the morning. On d 7 after presumptive estrus (i.e., d 18 of after starting the synchronization protocol), the ovaries of cows were scanned by ultrasonography using a 7.5-MHz linear array (Aloka SSD-500, Aloka, Tokyo, Japan) and cows with a visible corpus luteum were eligible to receive ET. Cows eligible to receive ET received an injection of $0.1 \mathrm{mg}$ of GnRH (Fertagyl, $0.1 \mathrm{mg} / \mathrm{mL}$ 
of gonadorelin; MSD Animal Health, São Paulo, Brazil) concurrent with ET performed by a single experienced veterinarian.

\section{Pregnancy Diagnosis and Resynchronization for Embryo Transfer}

All cows were evaluated for pregnancy on d 31 of presumptive gestation (i.e., $24 \mathrm{~d}$ after ET). Diagnosis was performed using transrectal ultrasonography of the uterus and its contents and characterized by visualization of a live embryo with a heartbeat. Cows diagnosed as pregnant on d 31 were reexamined by transrectal ultrasonography $4 \mathrm{wk}$ later, on d 59 of presumptive pregnancy. Pregnancy per ET was calculated as the number of pregnant cows on d 31 or 59 of gestation divided by the total number of cows that received ET. Pregnancy loss was calculated as the number of cows that lost a pregnancy between gestation d 31 and 59 divided by the number of pregnant cows on $\mathrm{d} 31$. Cows diagnosed as nonpregnant on d 31 or 59 had their estrous cycle resynchronized for timed ET using exactly the same timed protocol described for the first ET.

Pregnancy per ET on d 31 and 59, and pregnancy loss were calculated for the first 2 postpartum ET for each cow. Pregnancy per ET for all ET performed in the first 300 DIM was calculated only based on diagnosis performed on d 59 of presumptive pregnancy.

\section{Calculations of 21-Cycle Service Rate, 21-d Cycle Pregnancy Rate, and Days Open}

Service rate was calculated assuming that every eligible cow (those past the voluntary waiting period of 43 DIM and nonpregnant) should receive a breeding every $21 \mathrm{~d}$. Cows became noneligible for subsequent breeding if they were diagnosed pregnant on d 59 of gestation, became "do not breed," left the herd, or completed 300 DIM, whichever happened first.

Days open was calculated for every cow as the interval from calving to pregnancy based on the diagnosis performed on d 59 of gestation. Cows that became "do not breed," left the herd without a pregnancy diagnosis, or remained nonpregnant by 300 DIM were censored using the date of whichever happened first.

\section{Study Design and Statistical Analyses}

The study design was a prospective cohort study. A sample size was calculated using the POWER procedure of SAS version 9.4 (SAS/STAT, SAS Institute Inc., Cary, NC) based on the assumption that $50 \%$ of the cows would develop at least one inflammatory disease postpartum (Ribeiro et al., 2013, 2016) and that cows with inflammatory diseases would have at least an 11 percentage point decrease in $\mathrm{P} / \mathrm{ET}$. The mean $\mathrm{P} / \mathrm{ET}$ of the farm in the preceding year was $40 \%$. Therefore, it was assumed that cows without inflammatory diseases would have a P/ET of $45 \%$ and those with inflammatory diseases the $\mathrm{P} / \mathrm{ET}$ would be $34 \%$. The sample size, calculated using a likelihood ratio chi-squared test for 2 proportions with $\alpha=0.05$ and $\beta=0.20$, resulted in a total of 620 cows (310 per group). Because of potential attrition caused by diseases, a minimum sample size of 700 cows was deemed necessary for the study.

Binary data were analyzed by logistic regression using generalized linear mixed models with the GLIMMIX procedure of SAS (SAS/STAT, SAS Institute Inc.) fitting a binary distribution. Continuous data were analyzed by linear mixed models using the MIXED procedure of SAS (SAS/STAT, SAS Institute Inc.). Time to an event was analyzed by the Cox's hazard regression method using the PHREG procedure of SAS (SAS/ STAT, SAS Institute Inc.).

Risk factors for UTD and NUTD were investigated using univariable analyses. Factors considered were season of calving (cool vs. hot), lactation group (1 vs. 2 vs. $>2$ lactations), breed (50/50 Holstein-Gyr vs. $75 / 25$ Holstein-Gyr), calving problems (no vs. yes), sex of the calf (female vs. male), BCS at calving, the greatest concentration of haptoglobin in serum on d 0 to 2 postpartum, the greatest concentration of fatty acids in serum on d 0 to 2 postpartum, blood BHB concentration on $\mathrm{d} 8$ postpartum, days with subclinical hypocalcemia ( 0 vs. 1 vs. $>1$ ), the smallest concentration of $\mathrm{Mg}$ in serum on d 0 to 2 postpartum, and the smallest concentration of $\mathrm{P}$ in serum on d 0 to 2 postpartum. Variables associated with the response based on $P \leq$ 0.10 were considered for inclusion in the multivariable models. The multivariable models included all explanatory variables as fixed effects that met the significance at $P \leq 0.10$ and a backward stepwise elimination procedure was applied, and at each step, the explanatory variable with largest $P$-value was removed if $P>0.10$. At each step, model fit was assessed using the Akaike's information criterion. Therefore, the final multivariable models included only fixed effects with $P \leq 0.10$. The Kenward-Roger method was used to calculate the approximate denominator degrees of freedom for the $F$-tests in the multivariable statistical models.

To evaluate the association between inflammatory diseases and fertility of cows receiving ET, data were analyzed with multivariable logistic regression models with diseases classified as UTD or NUTD. For re- 
sponses with a single measurement per cow, the models included the fixed effects of UTD, NUTD, and the interaction between UTD and NUTD. For responses with more than one measurement per cow such as 21-d cycle service rate, 21-d cycle pregnancy rate, and $\mathrm{P} /$ ET for all ET, the models also included the fixed effects of replicate (21-d interval or ET number), the interaction between UTD and replicate, and the interaction between NUTD and replicate, and the random effect of cow nested within UTD and NUTD group. The Kenward-Roger method was used to calculate the approximate denominator degrees of freedom for the $F$-tests in the statistical models.

Milk yield, BCS, and concentrations of analytes in blood were analyzed with mixed models with the fixed effects of UTD, NUTD, the interaction between UTD and NUTD, time (day or week), the interactions between UTD and time, NUTD and time, and UTD and NUTD and time, and the random effect of cow nested within UTD and NUTD group. Time, day or week, was the factor in the REPEATED statement and the covariance structure that resulted in the best fit assessed based on the smallest Akaike's information criterion was selected. The first-order autoregressive structure was the most common covariance structure applied. The Kenward-Roger method was used to calculate the approximate denominator degrees of freedom for the $F$-tests in the statistical models. In all models for continuous data, the distribution of residuals and homogeneity of variance were evaluated after fitting the statistical models. Data that violated the assumptions of normality were subjected to transformation selected by a macro in SAS (SAS/STAT; SAS Institute Inc.) using the Box-Cox power transformation before statistical analyses (Piepho, 2009). The least squares means and standard error of the means of transformed data were back-transformed for data presentation according to Jørgensen and Pedersen (1998).

Time to event such as days open or days to leaving the herd were analyzed with the Cox's hazard regression method with models that included the fixed effects of UTD, NUTD, and the interaction between UTD and NUTD. If the interaction between UTD and NUTD resulted in $P>0.10$, it was then removed from the final model. Proportionality of the hazards was assessed using the ASSESS PH and RESAMPLE functions in the PHREG procedure of SAS to perform graphical and numerical evaluations of the Martingale residuals and compute the $P$-value of the Kolmogorov-type supremum test (Lin et al., 1993).

Differences with $P \leq 0.05$ were considered significant and $0.05<P \leq 0.10$ were considered tendencies.

\section{RESULTS}

\section{Risk Factors and Prevalence of Clinical and Subclinical Diseases}

Uterine diseases affected $63.3 \%$ and NUTD affected $20.6 \%$ of the cows in the study. The prevalence of individual UTD and NUTD according to parity group is depicted in Table 2. The most prevalent UTD was subclinical endometritis, followed by clinical endometritis, then metritis and retained placenta. Because subclinical endometritis was included as a UTD, the proportion of endometrial PMN in cows without UTD was smaller $(P<0.001)$ than in those with UTD $(3.0 \pm 1.7$ vs. 25.9 $\pm 1.0 \%)$. No difference $(P=0.80)$ in the proportion of endometrial PMN was observed between cows without or with NUTD $(14.7 \pm 0.8$ vs. $14.2 \pm 1.8 \%)$. Of the 733 cows, $26.2 \%(\mathrm{n}=192)$ were diagnosed with multiple UTD. The diagnosis of the first and last disease event in cows that developed UTD had, respectively, a mean $( \pm \mathrm{SD})$ of $16.0 \pm 11.0$ and $28.6 \pm 10.7$ and a median of 19 and $27 \mathrm{~d}$ postpartum. Approximately $35 \%$ of primiparous and multiparous cows calved between 0001 and $0600 \mathrm{~h}$ and only $10 \%$ of cows calved between 1801 and $0000 \mathrm{~h}$ (Table 2).

The diagnosis of the first and last disease event in cows that developed NUTD had, respectively, a mean $( \pm \mathrm{SD})$ of $15.7 \pm 14.4$ and $35.4 \pm 16.1$ and a median of 16.0 and $32.0 \mathrm{~d}$ postpartum. The most prevalent NUTD was mastitis with only a small proportion of cows diagnosed with other NUTD (Table 2). Of the 733 cows, only $1.9 \%(\mathrm{n}=14)$ were diagnosed with multiple NUTD in the first $60 \mathrm{~d}$ postpartum. Of the 118 cows diagnosed with mastitis, 80 had a single case, 30 had 2 cases, 6 had 3 cases, and 2 cows had 4 cases, resulting in a total of 166 cases of clinical mastitis. Of the 166 cases of mastitis, bacterial cultures included 33 cases of Streptococcus agalactiae, 13 cases of S. uberis, 7 cases of S. dysgalactiae, 2 cases of Staphylococcus coagulase negative, 2 cases of Corynebacterium sp., 1 cases of Bacillus sp., 9 cases of other gram-positive bacteria, 15 cases of coliform bacteria, 1 case of yeast, 2 contaminated samples with colonies of multiple microorganisms, and 81 samples with no growth.

Numerous risk factors were identified for UTD in the univariable analyses (Table 3), including season of calving, parity $>2$, breed, calving problems, days with subclinical hypocalcemia $>1$, blood concentration of BHB, and serum concentrations of haptoglobin, $\mathrm{Mg}$, and $\mathrm{P}$. After the multivariable analyses (Table 3 ), the risk factors that remained significant for UTD were season of calving, parity group $>2$, calving problems, days with 
Table 2. Descriptive statistics of data from the 733 cows enrolled in the study according to parity group

\begin{tabular}{|c|c|c|c|}
\hline $\begin{array}{l}\text { Item, mean } \pm S D \\
\text { or } \%(n / n)\end{array}$ & All cows & Primiparous & Multiparous \\
\hline Cows, $\mathrm{n}$ & 733 & $34.4(252 / 733)$ & $65.6(481 / 733)$ \\
\hline \multicolumn{4}{|l|}{ Distribution of calving } \\
\hline 0001 to $0600 \mathrm{~h}$ & $35.2(258 / 733)$ & $36.9(93 / 252)$ & $34.3(165 / 481)$ \\
\hline 0601 to $1200 \mathrm{~h}$ & $25.6(188 / 733)$ & $25.8(65 / 252)$ & $25.6(123 / 481)$ \\
\hline 1201 to $1800 \mathrm{~h}$ & $28.8(211 / 733)$ & $26.6(67 / 252)$ & $29.9(144 / 481)$ \\
\hline 1801 to $0000 \mathrm{~h}$ & $10.4(76 / 733)$ & $10.7(27 / 252)$ & $10.2(49 / 481)$ \\
\hline \multicolumn{4}{|l|}{ Season of calving } \\
\hline Cool & $25.2(185 / 733)$ & $25.8(65 / 252)$ & $25.0(120 / 481)$ \\
\hline Hot & $74.8(548 / 733)$ & $74.2(187 / 252)$ & $75.0(361 / 481)$ \\
\hline BCS at calving, 1 to 5 & $3.28 \pm 0.30$ & $3.31 \pm 0.25$ & $3.27 \pm 0.33$ \\
\hline Calving problems ${ }^{1}$ & $8.7(64 / 733)$ & $7.1(18 / 252)$ & $9.6(46 / 481)$ \\
\hline Uterine diseases $^{2}$ & $63.3(464 / 733)$ & $58.0(146 / 252)$ & $66.1(318 / 481)$ \\
\hline Retained placenta & $11.4(84 / 733)$ & $8.7(22 / 252)$ & $12.9(62 / 481)$ \\
\hline Metritis & $13.8(101 / 733)$ & $11.5(29 / 252)$ & $15.0(72 / 481)$ \\
\hline Clinical endometritis & $34.5(243 / 704)$ & $24.8(61 / 246)$ & $39.7(182 / 458)$ \\
\hline Subclinical endometritis & $48.5(333 / 686)$ & $46.1(112 / 243)$ & $49.9(221 / 443)$ \\
\hline Nonuterine diseases $^{3}$ & $20.6(151 / 733)$ & $8.7(22 / 252)$ & $26.8(129 / 481)$ \\
\hline Mastitis & $16.1(118 / 733)$ & $7.1(18 / 252)$ & $20.8(100 / 481)$ \\
\hline Lameness & $4.1(30 / 733)$ & $1.6(4 / 252)$ & $5.4(26 / 481)$ \\
\hline Pneumonia & $1.2(9 / 733)$ & 0 & $1.9(9 / 481)$ \\
\hline Displaced abomasum & $0.7(5 / 733)$ & 0 & $1.0(5 / 481)$ \\
\hline \multicolumn{4}{|l|}{ Haptoglobin, ${ }^{4} \times 100 \mathrm{AU} / \mathrm{mL}$} \\
\hline Mean & $3.93 \pm 3.56$ & $4.70 \pm 4.04$ & $3.52 \pm 3.20$ \\
\hline Largest value & $6.42 \pm 5.56$ & $7.42 \pm 5.94$ & $5.89 \pm 5.28$ \\
\hline \multicolumn{4}{|l|}{ Fatty acids,${ }^{4} \mathrm{~m} M$} \\
\hline Mean & $0.48 \pm 0.24$ & $0.45 \pm 0.20$ & $0.49 \pm 0.25$ \\
\hline Largest value & $0.67 \pm 0.33$ & $0.64 \pm 0.33$ & $0.68 \pm 0.33$ \\
\hline $\mathrm{BHB},{ }^{5} \mathrm{~m} M$ & $0.78 \pm 0.37$ & $0.72 \pm 0.31$ & $0.81 \pm 0.39$ \\
\hline \multicolumn{4}{|l|}{ Days of $\mathrm{SCH}^{6}$} \\
\hline 0 & $33.7(247 / 733)$ & $48.0(121 / 252)$ & $26.2(126 / 481)$ \\
\hline 1 & $21.0(154 / 733)$ & $18.3(46 / 252)$ & $22.5(108 / 481)$ \\
\hline$>1$ & $45.3(332 / 733)$ & $33.7(85 / 252)$ & $51.3(247 / 481)$ \\
\hline \multicolumn{4}{|l|}{ Total $\mathrm{Ca},{ }^{4} \mathrm{~m} M$} \\
\hline Mean & $2.01 \pm 0.18$ & $2.08 \pm 0.15$ & $1.97 \pm 0.18$ \\
\hline Smallest value & $1.89 \pm 0.22$ & $1.98 \pm 0.18$ & $1.84 \pm 0.23$ \\
\hline \multicolumn{4}{|l|}{ Total Mg, ${ }^{4} \mathrm{~m} M$} \\
\hline Mean & $0.95 \pm 0.12$ & $0.97 \pm 0.11$ & $0.95 \pm 0.12$ \\
\hline Smallest value & $0.87 \pm 0.12$ & $0.90 \pm 0.13$ & $0.86 \pm 0.12$ \\
\hline \multicolumn{4}{|l|}{ Total $\mathrm{P}^{4} \mathrm{~m} M$} \\
\hline Mean & $1.37 \pm 0.25$ & $1.46 \pm 0.22$ & $1.33 \pm 0.25$ \\
\hline Smallest value & $1.13 \pm 0.25$ & $1.20 \pm 0.24$ & $1.08 \pm 0.24$ \\
\hline \multicolumn{4}{|l|}{ Milk yield } \\
\hline First 60 DIM, kg/d & $25.3 \pm 7.1$ & $21.4 \pm 5.8$ & $27.3 \pm 6.9$ \\
\hline Cumulative 60 DIM, kg & $1,498 \pm 467$ & $1,275 \pm 374$ & $1,615 \pm 467$ \\
\hline
\end{tabular}

${ }^{1}$ Includes dystocia, stillbirths, or twin calving.

${ }^{2}$ Includes retained placenta, metritis, clinical endometritis, and subclinical endometritis.

${ }^{3}$ Includes mastitis, displaced abomasum, pneumonia, and lameness.

${ }^{4}$ Serum samples analyzed on d 0,1 , and 2 postpartum. AU = arbitrary units.

${ }^{5}$ Whole blood sample analyzed on d $8 \pm 3$ postpartum.

${ }^{6}$ Subclinical hypocalcemia (SCH) based on serum total $\mathrm{Ca}<2.0 \mathrm{~m} M$ on $\mathrm{d} 0,1$, or 2 postpartum.

subclinical hypocalcemia $>1$, and serum concentrations of haptoglobin and $\mathrm{Mg}$.

Risk factors were identified for NUTD in the univariable analysis (Table 4), including parity group, days of subclinical hypocalcemia, and serum concentrations of fatty acids, $\mathrm{Mg}$, and $\mathrm{P}$; however, following multivariable analyses (Table 4) only parity group and serum concentration of $\mathrm{Mg}$ remained significant risk factors for NUTD.

\section{Impacts of Inflammatory Diseases on Reproduction}

Of the 733 cows enrolled, 675 cows $(92.1 \%)$ received at least $1 \mathrm{ET}$ (Table 5$)$. A greater $(P=0.02)$ proportion of cows with UTD received ET than cows without UTD. Conversely, a smaller $(P<0.001)$ proportion of cows with NUTD received ET than those without NUTD. Furthermore, of the 733 cows enrolled, 686 (93.6\%) were enrolled in the ovulation synchronization protocol 
at least once. For the first synchronization postpartum, $73.8 \%$ of the cows had a synchronized ovulation based on the presence of a corpus luteum on the day of ET. Both UTD $(P=0.02)$ and NUTD $(P=0.03)$ reduced the proportion of cows with a synchronized ovulation for ET, and UTD extended the interval from calving to first ET by $6 \mathrm{~d}$ (Table 5).

Maintenance of pregnancy following ET on d 59 of gestation was reduced $(P \leq 0.01)$ in UTD cows for the first (41.7 vs. $25.4 \%$ ) or all ET (46.4 vs. $36.2 \%$ ) compared with cows without UTD. Maintenance of pregnancy on d 59 was reduced $(P=0.02)$ in NUTD at the second ET (39.0 vs. 25.9\%; Table 5) compared with cows without NUTD. The reduced P/ET observed for cows with UTD combined with the reduced $(P=0.007) 21$-d service rate $(61.9$ vs. $54.8 \%)$ resulted in smaller $(P<0.001) 21$-d cycle pregnancy rate $(28.6$ vs. $19.9 \%$ ) and a $35 \%$ decrease in the hazard of pregnancy, culminating in an extra $32 \mathrm{~d}$ open (Table 6, Figure 1A). Nonuterine diseases did not affect the rate of pregnancy or days open (Tables 5 and 6, Figure 1B).

\section{Impacts of Inflammatory Diseases on Milk Yield, Body Condition, and Survival}

Inflammatory diseases were associated with altered milk yield. Cows diagnosed with UTD produced 94.5 $\mathrm{kg}$ more $(P=0.03)$ milk in the first 60 DIM than those without UTD (Figure 2A), an increase of $7.3 \%$, which was observed in wk 6 and 7 postpartum (Figure 2B). Conversely, cows that developed NUTD had decreased $(P<0.001)$ cumulative milk yield by $60 \mathrm{~d}$ postpartum, a reduction of $340 \mathrm{~kg}$ or $22.4 \%$ observed throughout the 60 DIM (Figures $2 \mathrm{~A}$ and $2 \mathrm{C}$ ). No interaction $(P>$ 0.30 ) was observed between UTD and NUTD for milk yield.

Inflammatory disease was associated with reduced BCS in the first $70 \mathrm{~d}$ postpartum (Figure 3). Cows that developed UTD had reduced BCS $(P=0.03)$ compared with those that did not develop UTD (Figure 3A), although the change in body condition from calving to $70 \mathrm{~d}$ postpartum did not differ $(P=0.12)$ between the 2 groups (without UTD $=-0.25 \pm 0.2$ vs. with UTD $-0.21 \pm 0.01)$. An interaction $(P=0.006)$ between

Table 3. Risk factors for uterine diseases ${ }^{1}$

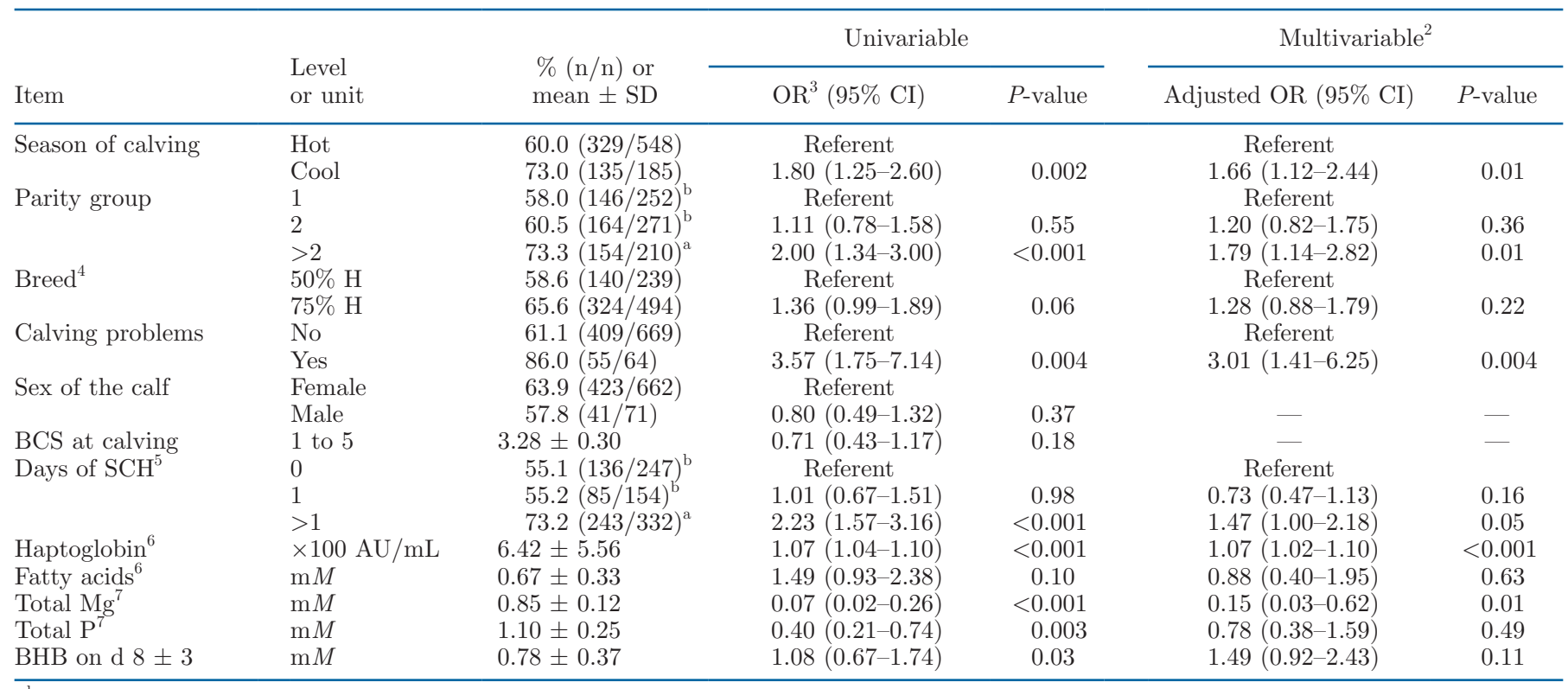

\footnotetext{
${ }^{\mathrm{a}, \mathrm{b}}$ Superscripts depicted for the categories of an explanatory variable differ in the multivariable model $(P<0.05)$.

${ }^{1}$ Uterine diseases include retained placenta, metritis, clinical endometritis, and subclinical endometritis.

${ }^{2}$ The multivariable models included only fixed effects from univariable models that resulted in $P \leq 0.10$.

${ }^{3} \mathrm{OR}=$ odds ratio.

${ }^{4}$ Crossbred cows were either $50 \%$ Holstein $(\mathrm{H})$ and $50 \%$ Gyr or $75 \% \mathrm{H}$ and $25 \%$ Gyr.

${ }^{5} \mathrm{SCH}=$ subclinical hypocalcemia based on serum total $\mathrm{Ca}<2.00 \mathrm{~m} M$.

${ }^{6}$ Largest value measured on $\mathrm{d} 0,1$, and 2 postpartum. $\mathrm{AU}=$ arbitrary units.

${ }^{7}$ Smallest value measured on d 0,1 , and 2 postpartum.
} 
Table 4. Risk factors for nonuterine diseases ${ }^{1}$

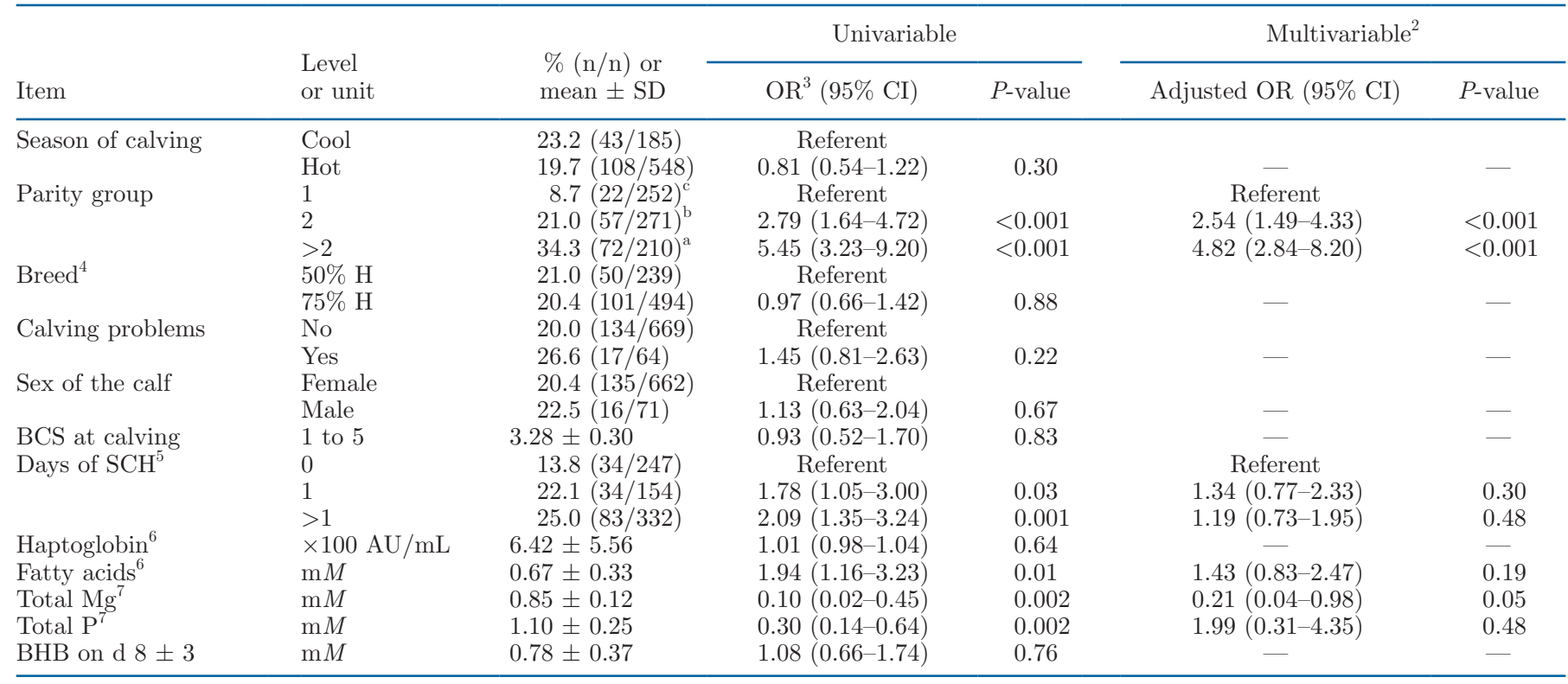

${ }^{\mathrm{a}-\mathrm{c}}$ Superscripts depicted for the categories of an explanatory variable differ in the multivariable model $(P<0.05)$.

${ }^{1}$ Nonuterine diseases include mastitis, displaced abomasum, pneumonia, and lameness.

${ }^{2}$ The multivariable models included only fixed effects from univariable models that resulted in $P \leq 0.10$.

${ }^{3} \mathrm{OR}=$ odds ratio.

${ }^{4}$ Crossbred cows were either 50\% Holstein (H) and 50\% Gyr or $75 \% \mathrm{H}$ and $25 \%$ Gyr.

${ }^{5} \mathrm{SCH}=$ subclinical hypocalcemia based on serum total $\mathrm{Ca}<2.00 \mathrm{mM}$.

${ }^{6}$ Largest value measured on $\mathrm{d} 0,1$, and 2 postpartum. AU $=$ arbitrary units.

${ }^{7}$ Smallest value measured on d 0,1 , and 2 postpartum.

Table 5. Impact of inflammatory diseases on reproductive performance of dairy cows receiving embryo transfer (ET)

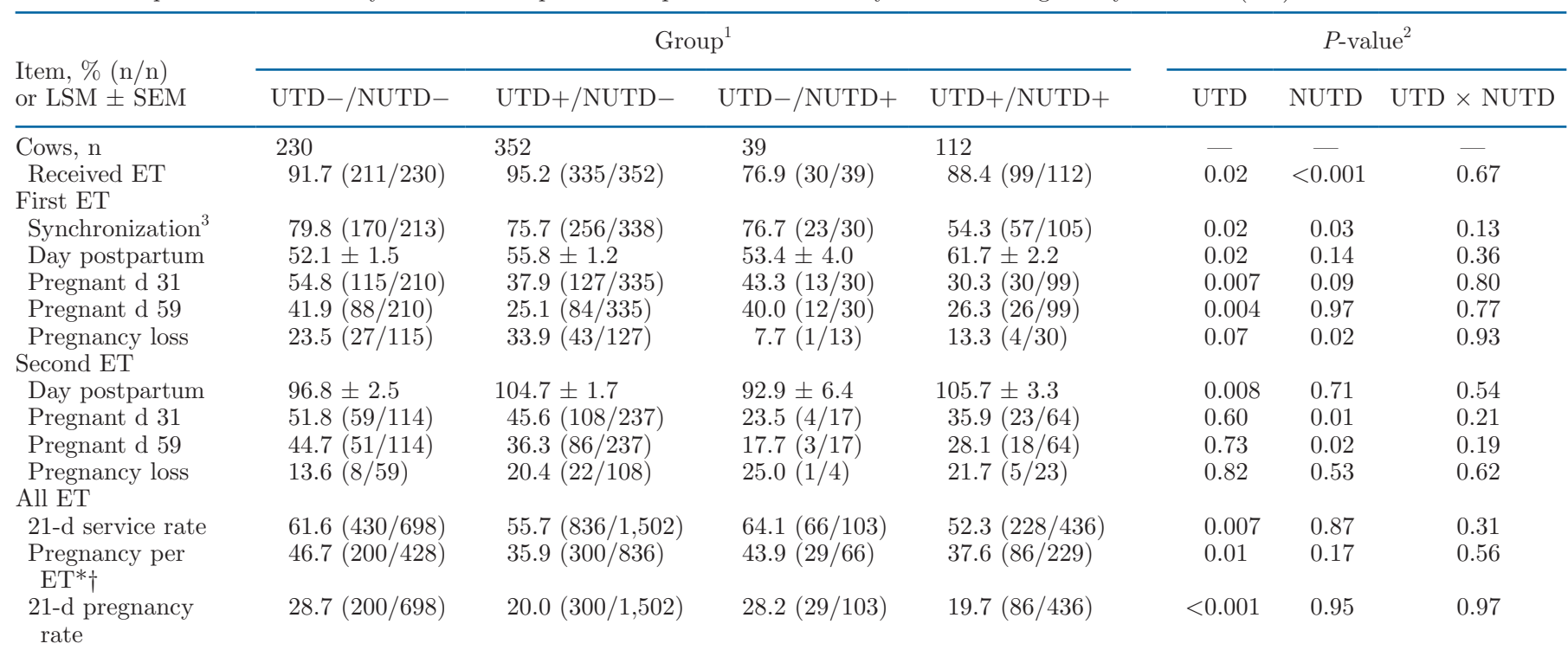

${ }^{1}$ Crossbred Holstein-Gyr cows were classified according to diagnosis of uterine diseases (UTD) or nonuterine diseases (NUTD) in the first 60 DIM into 4 groups: UTD $-/$ NUTD $-=$ UTD negative and NUTD negative; UTD +/NUTD $-=$ UTD positive and NUTD negative; UTD $-/$ NUTD + $=$ UTD negative and NUTD positive; and UTD $+/$ NUTD $+=$ UTD positive and NUTD positive.

${ }^{2} \mathrm{UTD}=$ effect of UTD; NUTD $=$ effect of NUTD; UTD $\times$ NUTD $=$ interaction between UTD and NUTD.

${ }^{3}$ Synchronization of ovulation based on the presence of a visible corpus luteum on the day of timed ET.

*Interaction between UTD and ET number $(P<0.05)$. †Interaction between NUTD and ET number $(P<0.05)$. 
Table 6. Cox's proportional hazard regression for days open in dairy cows receiving embryo transfer ${ }^{1}$

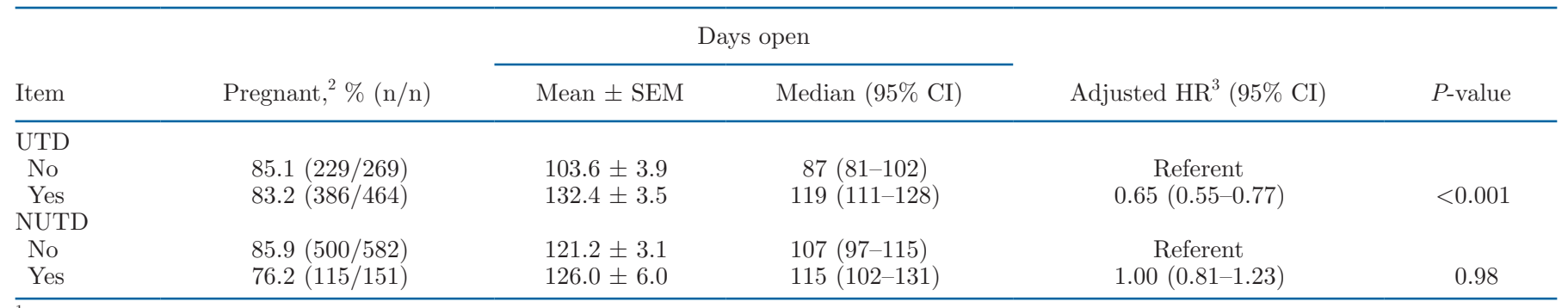

${ }^{1}$ Crossbred Holstein-Gyr cows were classified according to diagnosis of uterine diseases (UTD) or nonuterine diseases (NUTD) in the first 60 DIM. The interaction between UTD and NUTD was not significant $(P=0.86)$; therefore, results are presented for the main effects only.

${ }^{2}$ Pregnant $=$ cows that became pregnant in the first $300 \mathrm{~d}$ postpartum based on the diagnosis performed on $\mathrm{d} 59$ of the presumptive pregnancy. ${ }^{3} \mathrm{HR}=$ hazard ratio.

NUTD and day was observed for BCS and cows that developed NUTD had reduced BCS compared with those without NUTD but only at and after $28 \mathrm{~d}$ postpartum (Figure 3B). Cows with NUTD had increased $(P=0.003)$ loss of BCS in the first $70 \mathrm{~d}$ postpartum $(-0.19 \pm 0.01$ vs. $-0.27 \pm 0.03$ units $)$. No interaction $(P>0.50)$ was observed between UTD and NUTD for BCS or change in BCS in the first 70 DIM.

Of the 733 cows enrolled in the study, 645 (88\%) remained in the herd until 300 DIM. Cows that developed NUTD had a greater $(P=0.005)$ hazard (adjusted hazard ratio $=1.92 ; 95 \% \mathrm{CI}=1.22$ to 3.01 ) of leaving the herd than those that did not develop NUTD [no $\mathrm{NUTD}=10.3(60 / 582)$ vs. $\mathrm{UTD}=18.5 \%(28 / 151)]$. No association $(P=0.37)$ with UTD and no interaction $(P=0.92)$ between UTD and NUTD was associated with the hazard of removal from the herd.

\section{Associations Between Inflammatory Diseases and Concentrations of Analytes in Blood}

Cows with UTD had increased haptoglobin $(P=$ $0.03)$, decreased tCa $(P=0.0001)$, decreased $\mathrm{P}(P=$ $0.03)$, and tended to have increased BHB $(P=0.09)$ compared with cows without UTD (Figures 4 and $5)$. Cows with NUTD had increased fatty acids $(P=$ $0.0008)$, increased BHB, decreased $\mathrm{P}(P=0.01)$, and decreased $\mathrm{Mg}(P=0.03)$ compared with cows without NUTD (Figures 4 and 5). No interactions were observed between UTD and NUTD for concentrations of haptoglobin, fatty acids, tCa, $\mathrm{P}, \mathrm{Mg}$, or $\mathrm{BHB}$. Interactions $(P<0.01)$ between UTD and day postpartum were observed for haptoglobin, fatty acids, tCa, $\mathrm{P}$, and $\mathrm{Mg}$ as differences between cows with UTD and without UTD were only observed after the day of calving (Figures 4 and 5$)$. An interaction $(P=0.004)$ between NUTD and day was observed for tCa because cows with NUTD had smaller concentrations of tCa on $\mathrm{d} 0$ and 1 postpartum than cows without NUTD (Figure
5B). Furthermore, when the largest serum concentrations of haptoglobin and fatty acids, and the smallest serum concentrations of tCa, $\mathrm{P}$, and $\mathrm{Mg}$ from $\mathrm{d} 0$ to 2 postpartum from each cow were analyzed, the same pattern of response to UTD and NUTD were observed (Supplemental Figure S1; https://doi.org/10.3168/jds .2020-19070). Cows with UTD had the greatest concentration of haptoglobin, whereas those with NUTD had the greatest concentration of fatty acids. Cows with both UTD and NUTD had the smallest concentrations of tCa, $\mathrm{P}$, and $\mathrm{Mg}$ in serum.

\section{DISCUSSION}

Inflammatory diseases are known to be prevalent in the early postpartum period in dairy cows and the present prospective cohort study identified risk factors for UTD and NUTD and the association of those diseases with reproduction of cows receiving ET. The significant risk factors for UTD were multifactorial, including season of calving, parity, calving problems, subclinical hypocalcemia, and serum concentrations of haptoglobin and Mg. Risk factors identified for NUTD included parity group and serum concentration of $\mathrm{Mg}$. In the present study, inflammatory diseases were associated with a marked depression in reproduction in crossbred cows, corroborating previous reports of either high-producing cows in confinement systems or in grazing cows receiving AI (Santos et al., 2010; Ribeiro et al., 2013); however, the impact was associated mostly with UTD and only minor impacts were observed from NUTD. It is important to note that cows in the present study were bred only by timed ET, which was expected to bypass the effects that diseases might have on estrous expression, the developing follicle, and oocyte, fertilization, and embryo development for the first 7 d. Embryo recipients diagnosed with metritis in the early postpartum period have reduced P/ET, suggesting that uterine inflammation is a major contributor to 
pregnancy failure (Estrada-Cortés et al., 2019). Results herein corroborate those of Ribeiro et al. (2016) who showed that cows that had inflammatory diseases, particularly those with UTD diseases, have an impaired ability to maintain pregnancy after AI and ET.

Almost half of the cows in this study had uterine inflammation based on endometrial cytology on $28 \mathrm{~d}$ postpartum, and therefore, it is possible that endometrial function might have been altered by inflammatory molecules present in the uterus at the first ET. Another possibility is that cows with UTD had altered luteal lifespan that might interfere with maintenance of pregnancy. Furthermore, it is possible that UTD might influence expression of estrus, the endocrine milieu critical for endometrial receptivity of the conceptus, and affect conceptus and endometrial prostaglandin secretion needed for conceptus elongation and pla-
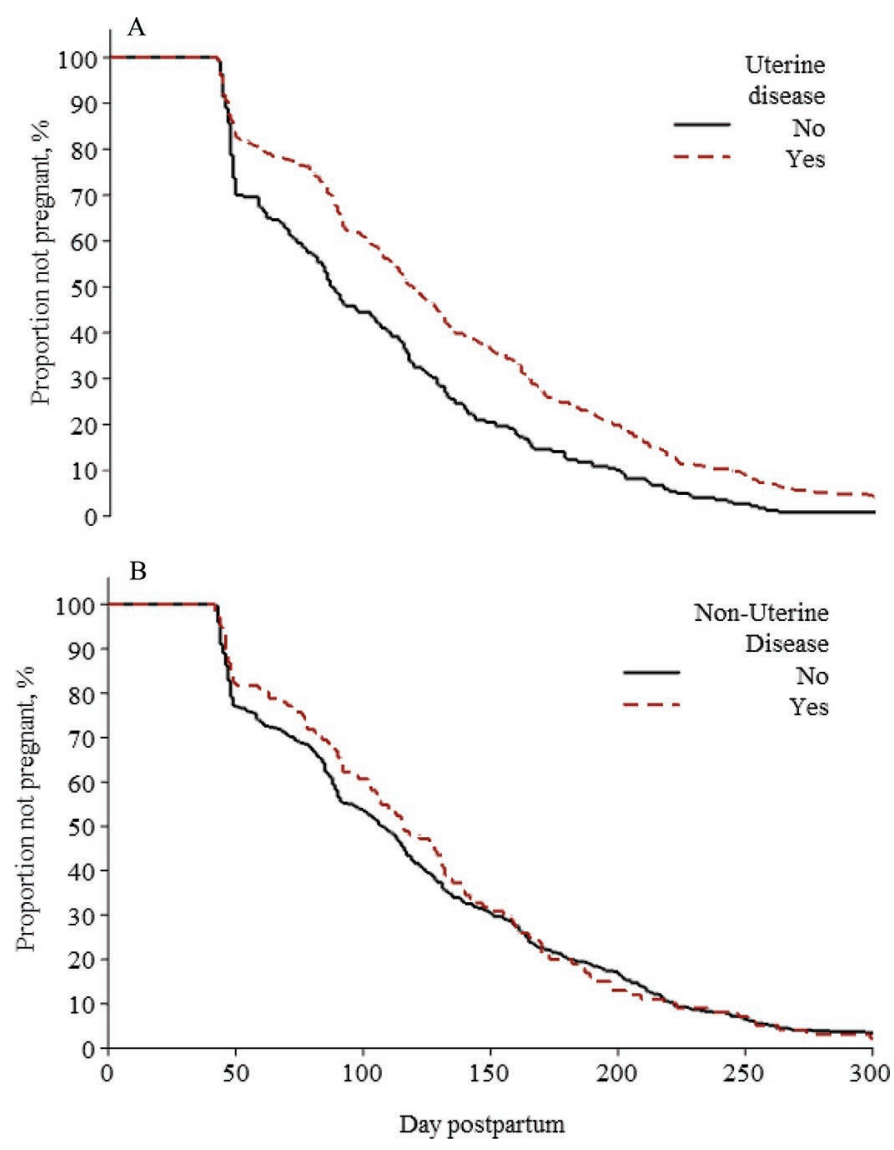

Figure 1. Survival curves for interval from calving to pregnancy in crossbred Holstein-Gyr cows receiving embryo transfer. Cows were classified according to diagnosis of uterine diseases (UTD) or nonuterine diseases (NUTD) in the first 60 DIM. (A) Effect of UTD (yes or no) on time to pregnancy $(P<0.001)$. (B) Effect of NUTD (yes or no) on time to pregnancy $(P=0.98)$. The interaction between UTD and NUTD was not significant $(P=0.86)$. centation (Brooks et al., 2014). Expression of estrus was not assessed in the present study, but it is well documented that cows that express estrus following an ovulation synchronization protocol that resembles that used in the present study have increased P/ET (Pereira et al., 2016). Finally, factors that predispose cows to develop uterine diseases, including those identified in the present study, might also influence maintenance of pregnancy in dairy cows. Pregnancy in cattle receiving ET depends on a transcriptome and metabolome that conveys a receptive endometrium for further conceptus development and maintenance of pregnancy. An elegant experiment by Mazzoni et al. (2020) investigated the endometrial transcriptome of dairy cows immediately before receiving an in vitro-produced embryo between estrous cycle d 6 and 8. Cows were subsequently slaughtered and pregnancy determined. As anticipated, cows that maintained pregnancy up to slaughter had an endometrial transcriptome that differed from those that failed to maintain pregnancy. Among the differentially expressed genes and subsequent pathways that differed in the $\mathrm{d} 6$ to 8 endometrium in cows that maintained pregnancy included transcripts involved in inflammation and in the balance between pro- and antiinflammatory responses that lead to tolerance for the conceptus (Mazzoni et al., 2020). It is conceivable that UTD results in endometrial inflammation that not only affects the transcriptome (Horlock et al., 2020), but the microbiota present in the uterus of cows with UTD might also differ and be less conducive to estrous cyclicity and pregnancy (Moore et al., 2019).

Inflammation in early lactation has been shown to disrupt early embryo development during the preimplantation period with reduced morula quality, conceptus elongation, and survival in dairy cows (Ribeiro et al., 2016). Products of induced endometrial inflammation are known to compromise early embryo development in vitro (Hill and Gilbert, 2008). It is unquestionable that bacterial products and mediators of the inflammatory cascade, including some proinflammatory cytokines, impair fertilization and reduce meiotic competence and development of in vitro-produced embryos to the blastocyst stage (Soto et al., 2003; Hansen et al., 2004), and alter granulosa cell and oocyte mRNA expression (Piersanti et al., 2019). These effects of inflammation on the follicle, oocyte, and early embryo help explain the reduction in fertilization, conceptus development, and pregnancy per AI observed in dairy cows that develop UTD (Ribeiro et al., 2016). In addition, when virgin dairy heifers were subjected to endometrial inflammation by utero-pathogenic bacteria, the transcriptome was altered 3 mo later in the endometrium, oviduct, and granulosa cells compared with control heifers (Hor- 

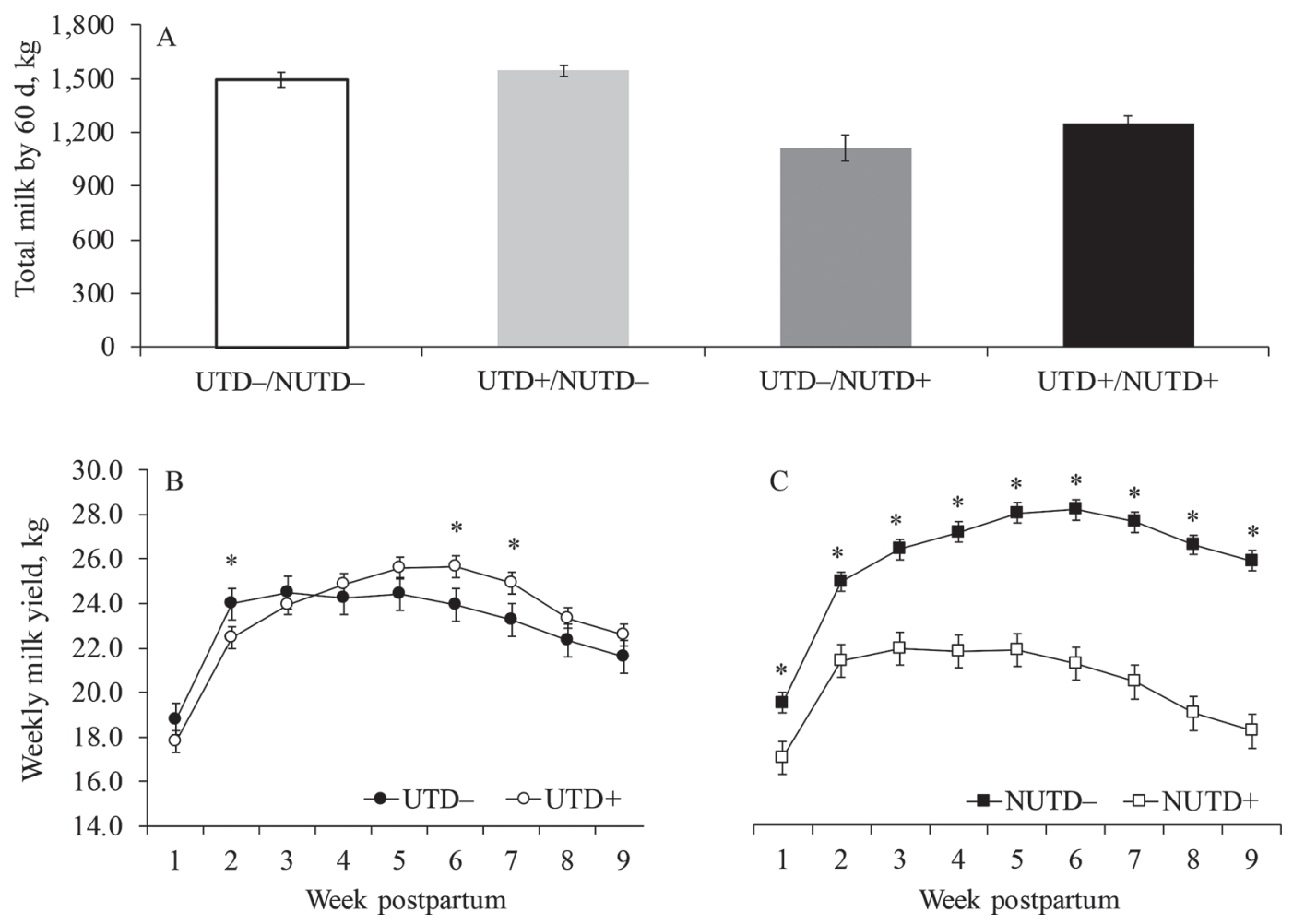

Figure 2. Cumulative milk yield (A) in the first $60 \mathrm{~d}$ postpartum according to uterine diseases (UTD) and nonuterine diseases (NUTD), and weekly milk yield in cows according to diagnosis of UTD (B) or NUTD (C). Crossbred Holstein-Gyr cows were classified according to diagnosis of UTD or NUTD in the first $60 \mathrm{~d}$ postpartum into 4 groups: UTD $-/$ NUTD $-=$ UTD negative and NUTD negative; UTD $+/$ NUTD $-=$ UTD positive and NUTD negative; UTD $-/$ NUTD $+=$ UTD negative and NUTD positive; and UTD $+/$ NUTD $+=$ UTD positive and NUTD positive. (A) Effects of UTD $(P=0.03)$, NUTD $(P<0.001)$, and interaction between UTD and NUTD $(P=0.30)$. (B) Effects of UTD $(P=0.44)$, week $(P<0.0001)$, and interaction between UTD and week $(P=0.008)$. $(\mathrm{C})$ Effects of NUTD $(P<0.001)$, week $(P<0.0001)$, and interaction between NUTD and week $(P<0.0001)$. Within week, ${ }^{*}$ denotes difference between groups $(P<0.05)$. Error bars represent SEM.

lock et al., 2020), suggesting a long-term effect of uteropathogenic bacteria on reproductive tissues that may mediate the impacts of UTD on reproduction observed in cows receiving ET in the present study.

During the inflammatory process of cows that develop diseases in early lactation, pathogen-associated molecular patterns, localized or systemic host responses, subsequent release of inflammatory mediators, and concurrent tissue injury may contribute to the reduced maintenance of pregnancy observed in cows following ET. Chapwanya et al. (2009) described elevated expression of genes encoding toll-like receptors, inflammatory mediators, and effector molecules such as amyloid precursor protein and antimicrobial peptides in the uterus of cows 2 wk postpartum during uterine involution. Toll-like receptors appeared to be functional as endometrial epithelial cells secreted prostaglandin $\mathrm{E}_{2}$ in response to detection of pathogen-associated molecular patterns, leading to increased expression of antimicrobial peptides and amyloid precursor proteins, providing nonspecific defenses against microbes on mucosal surfaces (Davies et al., 2008). Nonetheless, when the inflammatory response is exacerbated, disease develops, and excessive oxidative stress is often generated that damages tissue and causes dysfunction. Indeed, endometrial markers of oxidative stress have been associated with pregnancy success following ET in humans (Rahiminejad et al. 2016). Cows in the present study were synchronized to receive their first ET at 46 \pm 3 DIM, a period in which uterine inflammation may still have been present, based on the findings of others (Lima et al., 2013). Lima et al. (2013) performed consecutive cytological examinations of the endometrium and demonstrated that cows that had not resolved inflammation by 46 DIM had reduced pregnancy per AI and increased pregnancy loss compared with those that resolved postpartum uterine inflammation. It is possible that the local cellular changes taking place in the endometrium of cows that developed UTD make it less capable of establishing tolerance to conceptus alloantigens and favoring rejection by the maternal immune system, or that the altered endometrial molecular 

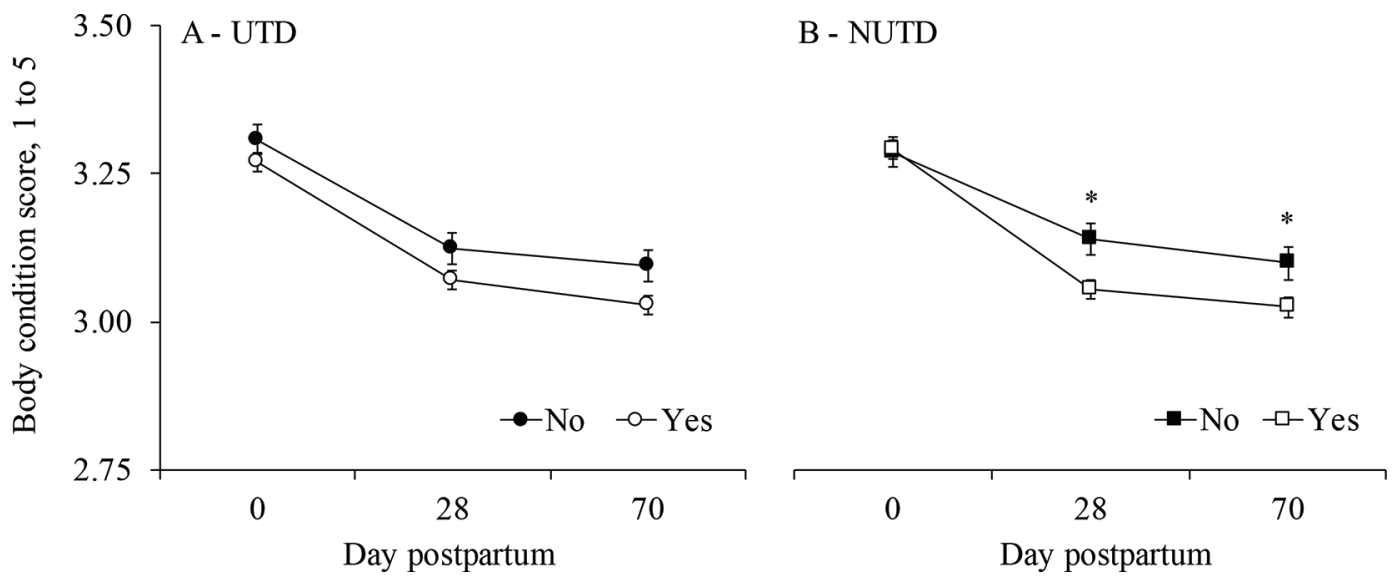

Figure 3. Body condition score of cows according to uterine diseases (UTD; A) or nonuterine diseases (NUTD; B) in the first $70 \mathrm{~d}$ postpartum. (A) Effect of UTD $(P=0.03)$ and interaction between UTD and day $(P=0.70)$. (B) Effect of NUTD $(P=0.04)$ and interaction between NUTD and day $(P=0.006)$. Within day, ${ }^{*}$ denotes difference between groups $(P<0.05)$. Error bars represent SEM.

signatures that persist for a long period after inflammation impair the ability of the uterus to support a pregnancy (Horlock et al., 2020).

The mechanisms of how NUTD reduce pregnancy in dairy cows receiving ET are not clear. Diagnosis of mastitis either before or after AI is associated with reduced pregnancy per AI, whereas mastitis after pregnancy had been diagnosed is associated with increased pregnancy loss (Santos et al., 2004). Isolation of major pathogens from milk of cows in the week of ET is associated with a marked reduction in $\mathrm{P} / \mathrm{ET}$, whereas cows with $\mathrm{SCC}$ above $4 \times 10^{5} / \mathrm{mL}$ have reduced P/ET (Barbosa et al., 2018). This suggests that active infection and inflammation of the mammary gland when ET is performed is detrimental to maintenance of pregnancy. Indeed, oocyte competence to develop to the blastocyst stage is reduced in cows with spontaneous or induced mastitis (Roth et al., 2013; Asaf et al., 2014). Here, cows with NUTD had reduced milk yield, which probably reflects the effect of those diseases on DMI and nutrient balance. Also, bacterial products and cytokines result in hyperthermia, a well-characterized phenomenon that compromises reproduction in cattle by interrupting embryonic development, interfering with preimplantation events, and altering uterine function (Edwards and Hansen, 1997; Sakatani et al., 2004). In the current study, cows received ET bypassing events related to oocyte quality, fertilization, and early embryo development. In cows diagnosed with NUTD, the diagnosis of the last disease event was at $35.4 \mathrm{~d}$ postpartum and the first ET occurred at $59.9 \mathrm{~d}$ postpartum, thus an interval of $24.5 \mathrm{~d}$. Unless the inflammation in the NUTD cows became chronic, it is unlikely that inflammatory mediators or hyperthermia would still be present after
3 wk to affect maintenance of pregnancy after ET (Edwards and Hansen, 1997; Hansen et al., 2004). In fact, half of the cases of mastitis, the predominant NUTD diagnosed, had no bacterial isolate identified presumably because the agent had been cleared from milk. Also, $24(14.5 \%)$ cases of mastitis the isolate agent was a gram-negative bacterium, which can cause an acute inflammatory response, but often of short duration. Therefore, it is more likely that inflammation caused by NUTD in early lactation might interfere with reproduction by compromising aspects related to follicle development or oocyte competence which can affect pregnancy many weeks following the insult (Ribeiro et al., 2016). On the other hand, if cows present infection and inflammation of the mammary gland in the week of ET, then the ongoing inflammatory process is associated with reduced maintenance of pregnancy following ET in dairy cows (Barbosa et al., 2018).

It is important to note that both UTD and NUTD reduced synchronization of ovulation for the first ET, and UTD delayed the first ET postpartum. Also, service rate for the subsequent cycles was reduced in cows that had UTD likely because of a combination of reduced synchrony of ovulation and reduced P/ET. Diseases and concurrent inflammatory response cause release of pathogen-associated and damage-associated molecular patterns that stimulate residing immune cells to release cytokines and, collectively, they can disrupt endocrine signaling and affect the developing follicle (Sheldon et al., 2009; Bromfield et al., 2015). This might explain the altered ability of cows to respond to the hormonal treatments and synchronize ovulation, which eventually affected the rate of pregnancy. In particular, the synchronization protocol used estradiol to induce ovu- 
lation, and pathogen-associated molecular patterns can disrupt the spontaneous LH surge in dairy cows (Lavon et al., 2008).

Cows with NUTD had a marked reduction in milk yield, which was not surprising given that most cases of NUTD involved mastitis that is known to depress productive performance. On the other hand, an unexpected increase in milk yield in the first 60 DIM was observed for cows with UTD, and the increase was less in cows that did not have NUTD (51 kg or 3.4\%) than in those that had NUTD (138 $\mathrm{kg}$ or $12.4 \%)$. Metritis is known to be associated with reduced milk yield (Sheldon et al., 2009), but of the 464 cows with UTD, only 101 or $21.8 \%$ had metritis and the remainder had either clinical or subclinical endometritis, which typically are not associated with systemic signs of disease or depression in milk yield. Also, because the increase in total milk yield observed for cows with UTD originated mostly within those with NUTD, it is possible that severity of NUTD, in particular mastitis, was less in those cows that also had UTD than those without UTD.

The risk of UTD or NUTD was dependent on several environmental and cow-level factors, many of which were associated with peripartum metabolism and

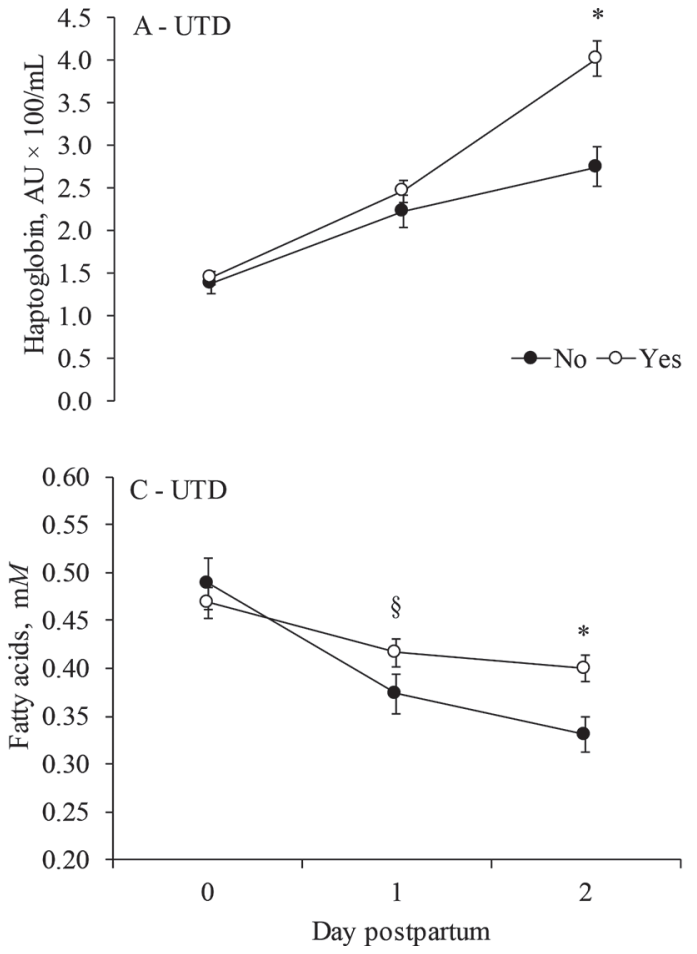

management of transition cows. It is interesting that cows calving during the cool season had greater risk of developing UTD than those calving in the hot season. It is clear that heat stress during the entire dry period suppresses lactation performance and immune function (Dahl et al., 2017), but less is known about the effects of dry period heat stress on disease incidence. Preliminary data suggest that cooling prepartum cows during the summer months to alleviate heat stress increases the risk of metritis (Santos et al., 2014). One of the risk factors for uterine disease is trauma caused during calving (Vieira-Neto et al., 2016), and larger calves are more likely to cause dystocia and trauma (Johanson and Berger, 2003); here calving problems was one of the risk factors identified for UTD. Heat stress and the resulting hyperthermia reduces gestation length and the BW of the newborn calf (Dahl et al., 2017), which might ease delivery and reduce the risk of dystocia. Also, as lactation number increased, the risk of UTD and that of NUTD also increased. Older cows are more likely to have retained placenta and mastitis (Markusfeld, 1987; Vieira-Neto et al., 2016; Taponen et al., 2017), which was observed in the present study. Nevertheless, NUTD reduced milk yield likely because

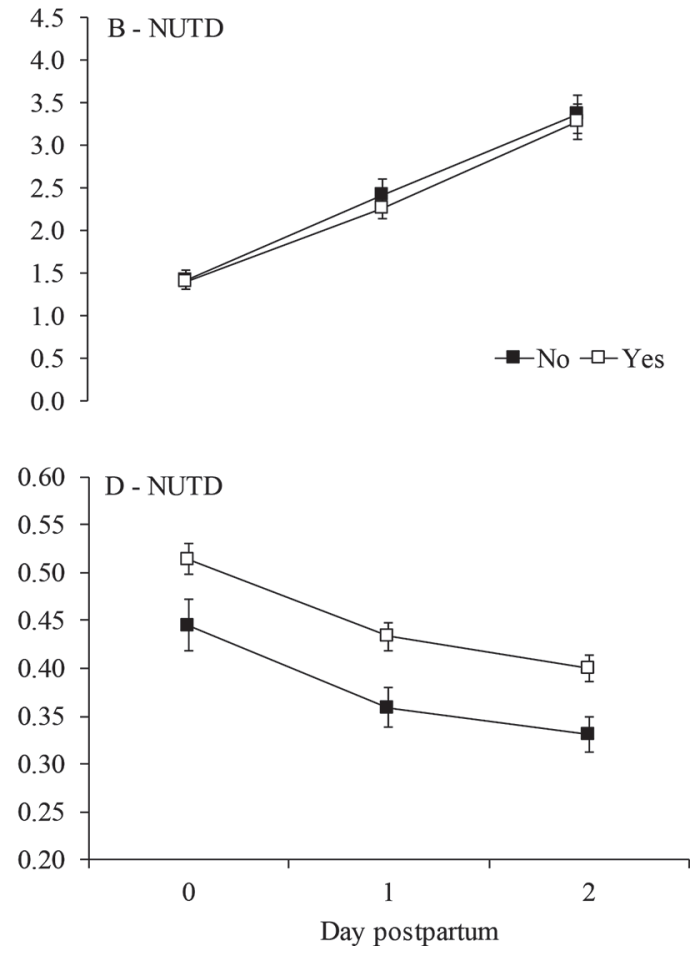

Figure 4. Serum concentration of haptoglobin according to uterine diseases (UTD; A) or nonuterine diseases (NUTD; B), and serum concentration of fatty acids according to UTD $(\mathrm{C})$ or NUTD (D). (A) Effect of UTD $(P=0.03)$ and interaction between UTD and day $(P=0.002)$. (B) Effect of NUTD $(P=0.66)$ and interaction between NUTD and day $(P=0.79)$. (C) Effect of UTD $(P=0.10)$ and interaction between UTD and day $(P=0.008)$. (D) Effect of NUTD $(P=0.0008)$ and interaction between NUTD and day $(P=0.76)$. Within day, ${ }^{*}$ denotes difference between groups $(P<0.05)$; within day, $\S$ denotes a tendency for difference between groups $(P=0.09)$. Error bars represent SEM. 

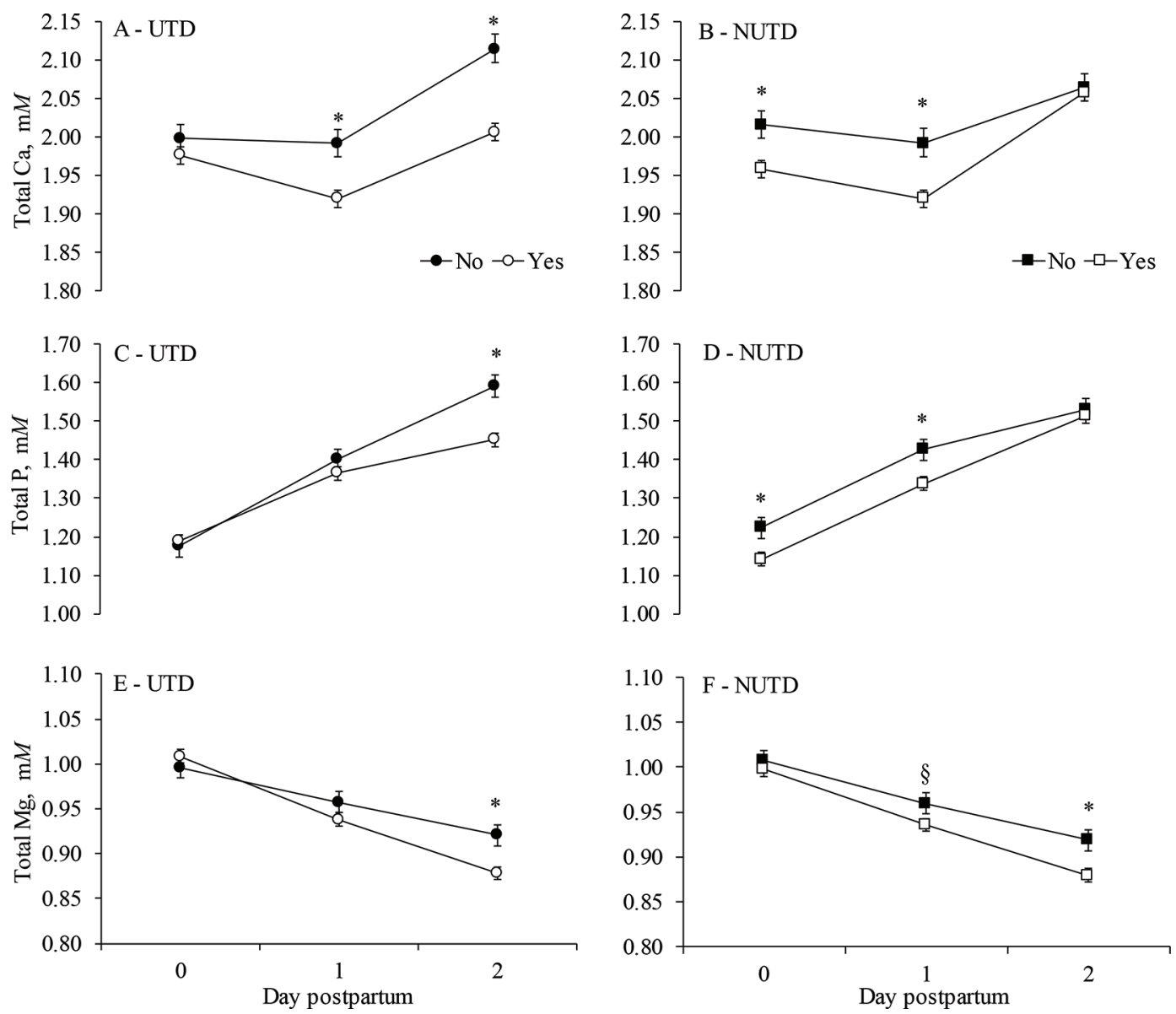

Figure 5. Serum concentration of total Ca according to uterine diseases (UTD; A) or nonuterine diseases (NUTD; B), serum concentration of total P according to UTD (C) or NUTD (D), and serum concentration of total Mg according to UTD (E) or NUTD (F). (A) Effect of UTD $(P=0.0001)$ and interaction between UTD and day $(P=0.003)$. (B) Effect of NUTD $(P=0.009)$ and interaction between NUTD and day $(P$ $=0.004)$. (C) Effect of UTD $(P=0.03)$ and interaction between UTD and day $(P=0.0007)$. (D) Effect of NUTD $(P=0.01)$ and interaction between NUTD and day $(P=0.12)$. (E) Effect of UTD $(P=0.15)$ and interaction between UTD and day $(P=0.0008)$. (F) Effect of NUTD $(P=0.03)$ and interaction between NUTD and day $(P=0.12)$. Within day, ${ }^{*}$ denotes difference between groups $(P<0.05)$ and $\S$ denotes a tendency to differ $(P=0.08)$. Error bars represent SEM.

mastitis directly affects the mammary gland resulting in a direct impairment or death of milk secreting cells.

The number of days with subclinical hypocalcemia and serum concentrations of haptoglobin and $\mathrm{Mg}$ were risk factors for UTD. The increase in haptoglobin on d 2 postpartum in cows that developed UTD is likely related to the activation of the inflammatory process with release of cytokines from residing immune cells, which in turn stimulate hepatic secretion of positive acute phase proteins (Cray et al., 2009). Others have shown that haptoglobin increases in the first few days after calving and the increment is greater with increased severity of uterine disease (Huzzey et al., 2009). Also, as cows developed more persistent subclinical hypocalcemia, the risk of UTD increased. It has been shown that hypocalcemia increases the risk of metritis, and one of the possible underlying mechanisms is the reduced innate immune function observed in cows with subclinical hypocalcemia (Martinez et al., 2012). Calcium is the most abundant mineral in milk and $\mathrm{Mg}$ is critical in the diet of dairy cows because little is stored in the body. The prepartum diet fed in the present study was not designed to prevent hypocalcemia with a DCAD of $+160 \mathrm{mEq} / \mathrm{kg}$. Also, although the dietary content of $\mathrm{K}$ pre- and postpartum was not excessive, dietary $\mathrm{Mg}$ was not high, which might have influenced the ability of cows to maintain adequate concentrations of tCa and $\mathrm{Mg}$ in serum. The incidence of cows with at least $1 \mathrm{~d}$ with subclinical hypocalcemia was high in both primiparous (52\%) and multiparous (73.8\%) cows, values greater than reported in Holstein cows in confinement herds in the United States (Reinhardt et al., 2011). Because alkalogenic diets and those that result in limited intake of $\mathrm{Mg}$ favor hypocalcemia and hypo- 
magnesemia (Goff, 2008), and those were risk factors for UTD, it is desirable that improvements in metabolic health by dietary means be implemented to reduce the risk of diseases that might interfere with fertility.

\section{CONCLUSIONS}

Inflammatory diseases are prevalent in the early postpartum period and have long-lasting impacts on maintenance of pregnancy in dairy cattle. Results from this prospective cohort study in a population of crossbred cows showed that $63.3 \%$ were affected by clinical or subclinical uterine diseases (or both) and $20.6 \%$ were affected by nonuterine diseases. Cows affected by uterine inflammation had a marked reduction in reproductive performance, likely because of localized effects that reduced service rate and maintenance of pregnancy following ET. Subsequently, the rate of pregnancy decreased and days open increased in cows with uterine inflammation. Nonuterine diseases, however, compromised milk yield in the first $60 \mathrm{~d}$ in lactation with minor impacts on reproduction. The fact that reproduction was affected to a greater degree in cows with uterine diseases than those with nonuterine diseases after ET suggests that uterine inflammation compromises its ability to support pregnancy, whereas nonuterine inflammation might affect the developing follicle, oocyte, fertilization, very early embryo development, or a combination of these. Risk factors for inflammatory diseases included blood markers of early postpartum inflammation, energy, and mineral metabolism. Collectively, these results suggest that improving the maintenance of pregnancy in dairy cows requires prevention of early postpartum diseases, in particular those affecting the uterus, by minimizing calving problems and disturbances of mineral and energy metabolism at the onset of lactation.

\section{ACKNOWLEDGMENTS}

The authors thank the owner and staff of Santa Luzia dairy farm from the Cabo Verde Group (Passos, MG, Brazil) for use of their cows and facilities. Partial funding for this project was provided by Phibro Animal Health (Teaneck, NJ) and the National Council for Scientific and Technological Development (CNPq) from Brazil under protocol number 134068/2019-0. Ingrid N. F. Edelhoff was supported by the graduate student fellowship from Coordenação de Aperfeiçoamento de Pessoal de Nível Superior (CAPES) from Brazil under the code 001 and by funding from the University of Florida. Marcos H. C. Pereira was supported by the graduate student fellowship from CAPES under protocol number
88882.317784/2019-01. The authors have not stated any conflicts of interest.

\section{REFERENCES}

Asaf, S., G. Leitner, O. Furman, Y. Lavon, D. Kalo, D. Wolfenson, and Z. Roth. 2014. Effects of Escherichia coli- and Staphylococcus aureus-induced mastitis in lactating cows on oocyte developmental competence. Reproduction 147:33-43. https://doi.org/10.1530/ REP-13-0383.

Banos, G., E. Wall, M. P. Coffey, A. Bagnall, S. Gillespie, G. C. Russell, and T. M. McNeilly. 2013. Identification of immune traits correlated with dairy cow health, reproduction and productivity. PLoS One 8:e65766. https://doi.org/10.1371/journal.pone .0065766 .

Barbosa, L. F. S. P., W. V. C. Oliveira, M. H. C. Pereira, M. B. Moreira, C. G. C. Vasconcelos, B. F. Silper, R. L. A. Cerri, and J. L. M. Vasconcelos. 2018. Somatic cell count and type of intramammary infection impacts fertility from in vitro produced embryo transfer. Theriogenology 108:291-296. https://doi.org/10.1016/j .theriogenology.2017.12.025.

Bradford, B. J., K. Yuan, J. K. Farney, L. K. Mamedova, and A. L. Carpenter. 2015. Invited review: Inflammation during the transition to lactation: New adventures with an old flame. J. Dairy Sci. 98:6631-6650. https://doi.org/10.3168/jds.2015-9683.

Bromfield, J. J., J. E. P. Santos, J. Block, R. S. Williams, and I. M. Sheldon. 2015. Physiology and Endocrinology Symposium: Uterine infection: Linking infection and innate immunity with infertility in the high-producing dairy cow. J. Anim. Sci. 93:2021-2033. https:/ /doi.org/10.2527/jas.2014-8496.

Brooks, K., G. Burns, and T. Spencer. 2014. Conceptus elongation in ruminants: Roles of progesterone, prostaglandin, interferon tau and cortisol. J. Anim. Sci. Biotechnol. 5:53. https://doi.org/10 $.1186 / 2049-1891-5-53$.

Carvalho, M. R., F. Peñagaricano, J. E. P. Santos, T. DeVries, B. McBride, and E. S. Ribeiro. 2019. Long-term impact of clinical disease postpartum on milk production, reproduction, and culling of dairy cows. J. Dairy Sci. 102:11701-11717. https://doi.org/10 $.3168 /$ jds.2019-17025.

Chapinal, N., M. E. Carson, S. J. LeBlanc, K. E. Leslie, S. Godden, M. Capel, J. E. P. Santos, M. W. Overton, and T. F. Duffield. 2012. The association of serum metabolites in the transition period with milk production and early-lactation reproductive performance. J. Dairy Sci. 95:1301-1309. https://doi.org/10.3168/jds.2011-4724.

Chapwanya, A., K. G. Meade, M. L. Doherty, J. J. Callanan, J. F. Mee, and C. O'Farrelly. 2009. Histopathological and molecular evaluation of Holstein-Friesian cows postpartum: Toward an improved understanding of uterine innate immunity. Theriogenology 71:1396-1407. https://doi.org/10.1016/j.theriogenology.2009.01 .006 .

Cooke, R. F., and J. D. Arthington. 2013. Concentrations of haptoglobin in bovine plasma determined by ELISA or a colorimetric method based on peroxidase activity. J. Anim. Physiol. Anim. Nutr. (Berl.) 97:531-536. https://doi.org/10.1111/j.1439-0396 2012.01298.x.

Cray, C., J. Zaias, and N. H. Altman. 2009. Acute phase response in animals: A review. Comp. Med. 59:517-526.

Dahl, G. E., S. Tao, and J. Laporta. 2017. Late gestation heat stress of dairy cattle programs dam and daughter milk production. J. Anim. Sci. 95:5701-5710. https://doi.org/10.2527/jas2017.2006.

Davies, D., K. G. Meade, S. Herath, P. D. Eckersall, D. Gonzalez, J. O. White, R. S. Conlan, C. O'Farrelly, and I. M. Sheldon. 2008. Tolllike receptors and antimicrobial peptide expression in the bovine endometrium. Reprod. Biol. Endocrinol. 6:53. https://doi.org/10 $.1186 / 1477-7827-6-53$.

Dickson, M. J., R. L. Piersanti, R. Ramirez-Hernandez, E. B. Oliveira, J. V. Bishop, T. R. Hansen, Z. Ma, K. C. Jeong, J. E. P. Santos, I. M. Sheldon, J. Block, and J. J. Bromfield. 2020. Experimentally induced endometritis impairs the developmental capacity of 
bovine oocytes. Biol. Reprod. ioaa069. https://doi.org/10.1093/ biolre/ioaa069.

Edwards, J., and P. Hansen. 1997. Differential responses of bovine oocytes and preimplantation embryos to heat shock. Mol. Reprod. Dev. 46:138-145. https://doi.org/10.1002/(SICI)1098 -2795(199702) 46:2<138::AID-MRD4>3.0.CO;2-R.

Elanco Animal Health. 2009. The 5-point body condition scoring system. Bulletin AI 10752. Elanco Animal Health, Greenfield, IN.

Estrada-Cortés, E., W. G. Ortiz, R. C. Chebel, E. A. Jannaman, J. I. Moss, F. C. de Castro, A. M. Zolini, C. R. Staples, and P. J. Hansen. 2019. Embryo and cow factors affecting pregnancy per embryo transfer for multiple-service, lactating Holstein recipients. Transl. Anim. Sci. 3:60-65. https://doi.org/10.1093/tas/txz009.

Galvão, K. N., M. Frajblat, S. B. Brittin, W. R. Butler, C. L. Guard, and R. O. Gilbert. 2009. Effect of prostaglandin $F_{2 \alpha}$ on subclinical endometritis. J. Dairy Sci. 92:4906-4913. https://doi.org/10.3168/ jds.2008-1984.

Goff, J. P. 2008. The monitoring, prevention, and treatment of milk fever and subclinical hypocalcemia in dairy cows. Vet. J. 176:50-57. https://doi.org/10.1016/j.tvjl.2007.12.020.

Hansen, P. J., P. Soto, and R. P. Natzke. 2004. Mastitis and fertility in cattle - Possible involvement of inflammation or immune activation in embryonic mortality. Am. J. Reprod. Immunol. 51:294-301. https://doi.org/10.1111/j.1600-0897.2004.00160.x.

Hill, J., and R. Gilbert. 2008. Reduced quality of bovine embryos cultured in media conditioned by exposure to an inflamed endometrium. Aust. Vet. J. 86:312-316. https://doi.org/10.1111/j.1751 $-0813.2008 .00326 . x$.

Horlock, A. D., R. L. Piersanti, R. Ramirez-Hernandez, F. Yu, Z. Ma, K. C. Jeong, M. J. D. Clift, J. Block, J. E. P. Santos, J. J. Bromfield, and M. Sheldon. 2020. Uterine infection alters the transcriptome of the bovine reproductive tract three months later. Reproduction 160:93-107. https://doi.org/10.1530/REP-19-0564.

Huzzey, J. M., T. F. Duffield, S. J. LeBlanc, D. M. Veira, D. M. Weary, and M. A. G. Von Keyserlingk. 2009. Short communication: Haptoglobin as an early indicator of metritis. J. Dairy Sci. 92:621-625. https://doi.org/10.3168/jds.2008-1526.

Johanson, J. M., and P. J. Berger. 2003. Birth weight as a predictor of calving ease and perinatal mortality in Holstein cattle. J. Dairy Sci. 86:3745-3755. https://doi.org/10.3168/jds.S0022 $-0302(03) 73981-2$.

Johnson, M. M., and J. P. Peters. 1993. Technical note: An improved method to quantify nonesterified fatty acids in bovine plasma. J. Anim. Sci. 71:753-756. https://doi.org/10.2527/1993.713753x.

Jørgensen, E., and A. R. Pedersen. 1998. How to obtain those nasty standard errors from transformed data-and why they should not be used. Biometry Research Unit-Internal report 7. Danish Institute of Agricultural Sciences, Aarhus, Denmark.

Lavon, Y., G. Leitner, T. Goshen, B. Braw-Tal, S. Jacoby, and D. Wolfenson. 2008. Exposure to endotoxin during estrus alters the timing of ovulation and hormonal concentrations in cows. Theriogenology 70:956-967. https://doi.org/10.1016/j.theriogenology .2008 .05 .058

Lima, F. S., R. S. Bisinotto, E. S. Ribeiro, L. F. Greco, H. Ayres, M. G. Favoreto, M. R. Carvalho, K. N. Galvão, and J. E. P. Santos. 2013. Effects of 1 or 2 treatments with prostaglandin $F_{2 \alpha}$ on subclinical endometritis and fertility in lactating dairy cows inseminated by timed artificial insemination. J. Dairy Sci. 96:6480-6488.

Lin, D. Y., L. J. Wei, and Z. Ying. 1993. Checking the Cox model with cumulative sums of martingale-based residuals. Biometrika 80:557-572. https://doi.org/10.1093/biomet/80.3.557.

Markusfeld, O. 1987. Periparturient traits in seven high dairy herds. Incidence rates, association with parity, and interrelationships among traits. J. Dairy Sci. 70:158-166. https://doi.org/10.3168/ jds.S0022-0302(87)79990-1.

Martinez, N., C. A. Risco, F. S. Lima, R. S. Bisinotto, L. F. Greco, E. S. Ribeiro, F. Maunsell, K. Galvão, and J. E. P. Santos. 2012. Evaluation of peripartal calcium status, energetic profile, and neutrophil function in dairy cows at low or high risk of developing uterine disease. J. Dairy Sci. 95:7158-7172. https://doi.org/10 $.3168 /$ jds.2012-5812.
Mazzoni, G., H. S. Pedersen, M. B. Rabaglino, P. Hyttel, H. Callesen, and H. N. Kadarmideen. 2020. Characterization of the endometrial transcriptome in early diestrus influencing pregnancy status in dairy cattle after transfer of in vitro-produced embryos. Physiol. Genomics 52:269-279. https://doi.org/10.1152/physiolgenomics .00027 .2020 .

McDougall, S., R. Macaulay, and C. Compton. 2007. Association between endometritis diagnosis using a novel intravaginal device and reproductive performance in dairy cattle. Anim. Reprod. Sci. 99:923. https://doi.org/10.1016/j.anireprosci.2006.03.017.

Moore, S. G., A. C. Ericsson, S. K. Behura, W. R. Lamberson, T. J. Evans, M. S. McCabe, S. E. Poock, and M. C. Lucy. 2019. Concurrent and long-term associations between the endometrial microbiota and endometrial transcriptome in postpartum dairy cows. BMC Genomics 20:405. https://doi.org/10.1186/s12864-019-5797-8.

Pereira, M. H. C., M. C. Wiltbank, and J. L. M. Vasconcelos. 2016. Expression of estrus improves fertility and decreases pregnancy losses in lactating dairy cows that receive artificial insemination or embryo transfer. J. Dairy Sci. 99:2237-2247. https://doi.org/10 $.3168 /$ jds.2015-9903.

Pérez-Báez, J., C. A. Risco, R. C. Chebel, G. C. Gomes, L. F. Greco, S. Tao, I. M. Thompson, B. C. do Amaral, M. G. Zenobi, N. Martinez, C. R. Staples, G. E. Dahl, J. A. Hernández, J. E. P. Santos, and K. N. Galvão. 2019. Association of dry matter intake and energy balance prepartum and postpartum with health disorders postpartum: Part I. Calving disorders and metritis. J. Dairy Sci. 102:9138-9150. https://doi.org/10.3168/jds.2018-15878.

Piepho, H. P. 2009. Data transformation in statistical analysis of field trials with changing treatment variance. Agron. J. 101:865-869. https://doi.org/10.2134/agronj2008.0226x.

Piersanti, R. L., J. E. P. Santos, I. M. Sheldon, and J. J. Bromfield. 2019. Lipopolysaccharide and tumor necrosis factor-alpha alter gene expression of oocytes and cumulus cells during bovine in vitro maturation. Mol. Reprod. Dev. 86:1909-1920. https://doi.org/ $10.1002 / \mathrm{mrd} .23288$.

Quinlan, K. P., and M. A. DeSesa. 1955. Spectrophotometric determination of phosphorus as molybdovanadophosphoric acid. Anal. Chem. 27:1626-1629. https://doi.org/10.1021/ac60106a039.

Rahiminejad, M. E., A. Moaddab, M. Ganji, N. Eskandari, M. Yepez, S. Rabiee, M. Wise, R. Ruano, and A. Ranjbar. 2016. Oxidative stress biomarkers in endometrial secretions: A comparison between successful and unsuccessful in vitro fertilization cycles. J. Reprod. Immunol. 116:70-75. https://doi.org/10.1016/j.jri.2016.05.003.

Reinhardt, T. A., J. D. Lippolis, B. J. McCluskey, J. P. Goff, and R. L. Horst. 2011. Prevalence of subclinical hypocalcemia in dairy herds. Vet. J. 188:122-124. https://doi.org/10.1016/j.tvjl.2010.03.025.

Ribeiro, E. S., G. Gomes, L. F. Greco, R. L. A. Cerri, A. Vieira-Neto, P. L. J. Monteiro Jr., F. S. Lima, R. S. Bisinotto, W. W. Thatcher, and J. E. P. Santos. 2016. Carryover effect of postpartum inflammatory diseases on developmental biology and fertility in lactating dairy cows. J. Dairy Sci. 99:2201-2220. https://doi.org/10.3168/ jds.2015-10337.

Ribeiro, E. S., F. S. Lima, L. F. Greco, R. S. Bisinotto, A. P. A. Monteiro, M. Favoreto, H. Ayres, R. S. Marsola, N. Martinez, W. W. Thatcher, and J. E. P. Santos. 2013. Prevalence of periparturient diseases and effects on fertility of seasonally calving grazing dairy cows supplemented with concentrates. J. Dairy Sci. 96:5682-5697. https://doi.org/10.3168/jds.2012-6335.

Roth, Z., A. Dvir, D. Kalo, Y. Lavon, O. Krifucks, D. Wolfenson, and G. Leitner. 2013. Naturally occurring mastitis disrupts developmental competence of bovine oocytes. J. Dairy Sci. 96:6499-6505. https://doi.org/10.3168/jds.2013-6903.

Sakatani, M., S. Kobayashi, and M. Takahashi. 2004. Effects of heat shock on in vitro development and intracellular oxidative state of bovine preimplantation embryos. Mol. Reprod. Dev. 67:77-82. https://doi.org/10.1002/mrd.20014.

Santos, J. E. P., R. S. Bisinotto, E. S. Ribeiro, F. S. Lima, L. F. Greco, C. R. Staples, and W. W. Thatcher. 2010. Applying nutrition and physiology to improve reproduction in dairy cattle. Soc. Reprod. Fertil. Suppl. 67:385-403. https://doi.org/10.7313/ upo9781907284991.030 . 
Santos, J. E. P., R. L. A. Cerri, M. A. Ballou, G. E. Higginbotham, and J. H. Kirk. 2004. Effect of timing of first clinical mastitis occurrence on lactational and reproductive performance of Holstein dairy cows. Anim. Reprod. Sci. 80:31-45. https://doi.org/10.1016/ S0378-4320(03)00133-7.

Santos, J. E. P., E. S. Ribeiro, E. Karakaya, K. N. Galvão, and F. S. Lima. 2014. Influences of heat stress and uterine diseases on reproduction of dairy cows. J. Dairy Sci. 97(Suppl. 1):202. (Abstr.)

Sheldon, I. M., J. Cronin, L. Goetze, G. Donofrio, and H. J. Schuberth. 2009. Defining postpartum uterine disease and the mechanisms of infection and immunity in the female reproductive tract in cattle. Biol. Reprod. 81:1025-1032. https://doi.org/10.1095/biolreprod .109.077370.

Soto, P., P. R. Natzke, and P. J. Hansen. 2003. Actions of tumor necrosis factor- $\alpha$ on oocyte maturation and embryonic development in cattle. Am. J. Reprod. Immunol. 50:380-388. https://doi.org/ 10.1034/j.1600-0897.2003.00101.x.

Sprecher, D. J., D. E. Hostetler, and J. B. Kaneene. 1997. A lameness scoring system that uses posture and gait to predict dairy cattle reproductive performance. Theriogenology 47:1179-1187. https:// doi.org/10.1016/S0093-691X(97)00098-8.

Taponen, S., E. Liski, A.-M. Heikkilä, and S. Pyörälä. 2017. Factors associated with intramammary infection in dairy cows caused by coagulase-negative staphylococci, Staphylococcus aureus, Streptococcus uberis, Streptococcus dysgalactiae, Corynebacterium bovis, or Escherichia coli. J. Dairy Sci. 100:493-503. https://doi.org/10 .3168/jds.2016-11465.

Vieira-Neto, A., F. S. Lima, J. E. P. Santos, R. D. Mingoti, G. S. Vasconcellos, C. A. Risco, and K. N. Galvão. 2016. Vulvovaginal laceration as a risk factor for uterine disease in postpartum dairy cows. J. Dairy Sci. 99:4629-4637. https://doi.org/10.3168/jds.2016 -10872 .

Wenz, J. R., G. M. Barrington, F. B. Garry, R. P. Dinsmore, and R. J. Callan. 2001. Use of systemic disease signs to assess disease severity in dairy cows with acute coliform mastitis. J. Am. Vet. Med. Assoc. 218:567-572. https://doi.org/10.2460/javma.2001.218.567.

\section{ORCIDS}

I. N. F. Edelhoff ๑ https://orcid.org/0000-0002-0373-2536

J. J. Bromfield (๑ https://orcid.org/0000-0001-5438-2137

J. L. M. Vasconcelos @ https://orcid.org/0000-0001-6324-3614

J. E. P. Santos ๑ https://orcid.org/0000-0003-3403-1465 